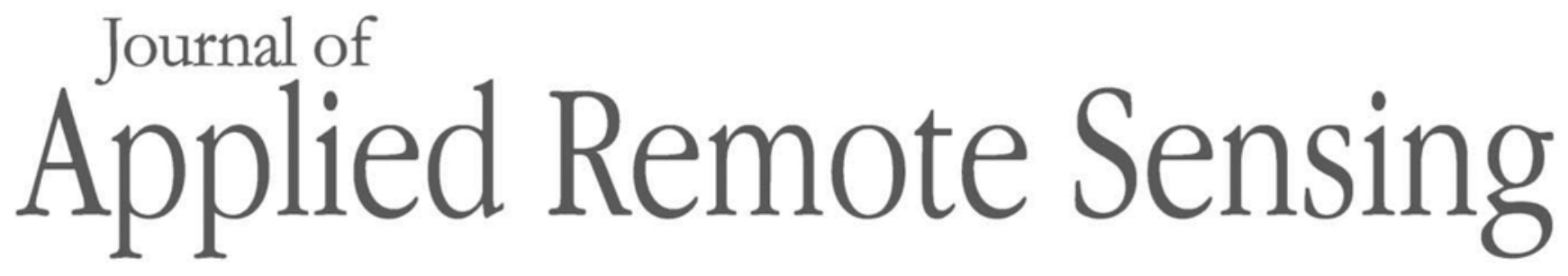

RemoteSensing.SPIEDigitalLibrary.org

\title{
Multiscale collection and analysis of submerged aquatic vegetation spectral profiles for Eurasian watermilfoil detection
}

Colin N. Brooks

Amanda G. Grimm

Amy M. Marcarelli

Richard J. Dobson 


\title{
Multiscale collection and analysis of submerged aquatic vegetation spectral profiles for Eurasian watermilfoil detection
}

\author{
Colin N. Brooks, ${ }^{\text {a,* Amanda G. Grimm, }}$ Amy M. Marcarelli, ${ }^{\text {b }}$ and \\ Richard J. Dobson ${ }^{\mathrm{a}}$ \\ ${ }^{a}$ Michigan Technological University, Michigan Tech Research Institute (MTRI), \\ Ann Arbor, Michigan, United States \\ ${ }^{\mathrm{b}}$ Michigan Technological University, Biological Sciences, Houghton, \\ Michigan, United States
}

\begin{abstract}
The ability to differentiate a non-native aquatic plant, Myriophyllum spicatum (Eurasian watermilfoil or EWM), from other submerged aquatic vegetation (SAV) using spectral data collected at multiple scales was investigated as a precursor to mapping of EWM. Spectral data were collected using spectroradiometers for SAV taken out of the water, from the side of a boat directly over areas of SAV and from a lightweight portable radiometer system flown from an unmanned aerial system (UAS). EWM was spectrally different from other SAV when using 651 spectral bands collected in ultraviolet to near-infrared range of 350 to $1000 \mathrm{~nm}$ but does not provide a practical system for EWM mapping because this exceeds the capabilities of available airborne hyperspectral imaging systems. Using only six spectral bands corresponding to an available multispectral camera or eight wetlands-centric bands did not reliably differentiate EWM from other SAV and assemblages. However, a modified version of the normalized difference vegetation index (mNDVI), using a ratio of red-edge to red light, was significantly different among dominant vegetation groups. Also, averaging the full range of spectral to $6510-\mathrm{nm}$ wide bands, similar to available hyperspectral imaging systems, provided the ability to identify EWM separately from other SAV. The UAS-collected spectral data had the lowest remote sensing reflectance versus the out-of-water and boatside data, emphasizing the need to collect optimized data. The spectral data collected for this study support that with relatively clear and calm water, hyperspectral data, and mNDVI, it is likely that UASbased imaging can help with mapping and monitoring of EWM. (c) The Authors. Published by SPIE under a Creative Commons Attribution 4.0 Unported License. Distribution or reproduction of this work in whole or in part requires full attribution of the original publication, including its DOI. [DOI: 10 .1117/1.JRS.13.037501]
\end{abstract}

Keywords: spectrometry; aquatic vegetation; profiles; Eurasian watermilfoil; unmanned.

Paper 181001 received Dec. 27, 2018; accepted for publication Jul. 3, 2019; published online Aug. 27, 2019.

\section{Introduction}

Aquatic vegetation provides a key refuge and growth habitat for a variety of plant and animal species in the shallow littoral regions on the edges of waterbodies, ${ }^{1,2}$ supporting more species per unit of primary production than open water (limnetic) zones. ${ }^{3}$ In a study of 14 of the world's largest lakes, Vadeboncoeur et al. ${ }^{3}$ found that more than $93 \%$ of fish species were found in the littoral zones and $72 \%$ of species were restricted to this area. Aquatic vegetation is a key factor controlling the structure and function of littoral zones, cycling nutrients, fixing carbon via photosynthesis, providing habitat for periphyton colonization and facilitating carbon and nutrient cycling by other primary producers. ${ }^{4,5}$ Aquatic vegetation is a source of both food and habitat for macroinvertebrates, fishes, and amphibians that are part of the food web. ${ }^{6}$ Finally, littoral zones are highly influenced by anthropogenic activity yet are poorly studied compared to

*Address all correspondence to Colin N. Brooks, E-mail: cnbrooks@mtu.edu 
limnetic zones. There are many aquatic invasive plant species, ${ }^{7}$ whose ecological and management impacts have resulted in control and treatment efforts in need of monitoring. ${ }^{8-12}$ Invasive aquatic plants can interfere with recreation, affect property values, impact subsistence fisheries harvests, increase nutrient loading, and deplete dissolved oxygen. ${ }^{13}$ For example, non-native Myriophyllum spicatum (Eurasian watermilfoil or "EWM") forms thick, submerged monotypic beds that typically reduce the richness, diversity, and distributions of benthic invertebrates and fishes in littoral zones. ${ }^{14}$ Challenges to the study of aquatic vegetation include relative difficulty of site access compared to terrestrial systems and attenuation of light in water, especially for freshwater systems.

Aquatic vegetation in littoral zones includes both species that emerge above the water surface (emergent aquatic vegetation) and those submerged below the surface (hereafter submerged aquatic vegetation, or SAV), which presents different opportunities and challenges for remote sensing. Mapping emergent vegetation with satellite imagery is relatively well established, in part because it does not require addressing issues related to light attenuation in water, absorption of infrared light by water, and turbidity ${ }^{15-17}$ Satellite imagery has been used successfully to map wetlands with predominantly emergent vegetation, including coastal tidal marshes, northern peatlands, inland freshwater marshes, and the Prairie Pothole region in the US and Canada. ${ }^{16,18}$

Previous work has indicated that the mapping of SAV can be possible using satellite imagery under certain conditions. Initial work such as Ackleson and Klemas ${ }^{19}$ showed feasibility for mapping a species of SAV using Landsat satellite imagery, noting the masking impact of optically deep water. Recent work by Brooks et al. has shown that SAV can be mapped over large areas of the coastal regions of the Laurentian Great Lakes using moderate-resolution satellite imagery such as Landsat, where there is sufficient optical depth due to relatively clear water and where SAV could be summarized in to a single class type dominated by the native alga Cladophora glomerata. ${ }^{20,21}$ Ozesmi and Bauer ${ }^{16}$ and Silva et al. ${ }^{17}$ have also shown that Landsat-type imagery is useful for large-scale SAV mapping at moderate resolution, particularly for areas of relatively clear water with limited light attenuation and low wind conditions during satellite overpass. Finer spatial resolution commercial satellite imagery such as QuickBird and WorldView data with a 1.0- to 2.4-m multispectral pixel size can also be used to discriminate between submerged and emergent or floating aquatic vegetation with limitations based on water conditions and acquisition costs. ${ }^{22-25}$ Fritz et al. ${ }^{26}$ have shown that 5-m resolution RapidEye imagery can effectively map four different SAV species. Dierssen et al. ${ }^{27}$ showed that airborne hyperspectral imagery can be effective in identifying areas of seagrass and Sargassum macroalgae.

The use of unmanned aerial system (UAS) is a relatively new area of research that can provide a source of mid-to-fine scale data ${ }^{28}$ that may provide better resolution and detection of SAV at appropriate scales for studying lake littoral zones. UAS can be deployed selectively during optimal weather conditions (low winds, more sunlight, optimal sun angles) and collect highresolution imagery that may help with differentiation of species of interest. ${ }^{29,30}$ The capabilities of UAS have been increasing in recent years, gaining the attention of ecologists as useful tools for meeting environmental data needs, including mapping. ${ }^{28,31,32}$

Understanding ecologically relevant patterns of macrophyte dynamics requires identification of individual SAV species that grow in mixed assemblages, which is possible if SAV species appear spectrally distinct when using scale-appropriate remote sensing. One tool for understanding whether plant species are spectrally distinct is field spectroradiometers, developed for applications such as identifying geological features and vegetation types. ${ }^{33,34}$ However, they have not been commonly used for spectral profiling of SAV. ${ }^{35}$ Some work has shown the capability to resolve distinct spectral signatures for aquatic plants using spectroradiometers in controlled growth environments, such as tanks of water. ${ }^{36,37}$ Underwood et al. ${ }^{38}$ and Williams et al. ${ }^{35}$ demonstrated capabilities to classify invasive SAV using airborne hyperspectral imagery. Whether similar classification would be possible using multispectral imagery at scales in between the field sampling scale and satellite scale has not yet been answered. Meeting the challenge of this intermediate-scale sensing is likely to require higher spatial resolution data than is available from satellite imagery, further supporting the utility of UAS for studying SAV in lake littoral zones. 
Brooks et al.: Multiscale collection and analysis of submerged aquatic vegetation...

EWM provides a test case to evaluate whether UAS-based spectrometry and multispectral imagery can be used to map SAV at scales relevant to management. In this study, we developed methods to rapidly create spectral profiles of aquatic plants of interest due to their invasion and management implications in our study region of the upper Laurentian Great Lakes. These methods would be used to understand how spectral data for an invasive species of interest, EWM, could be reliably collected and analyzed and how they compared between boat-based and UASbased imaging. We designed the study to address two central study questions:

1. Can spectral profiles of EWM be differentiated from those of other SAV species using spectroradiometer data and multispectral imagery collected in the upper Great Lakes?

2. Do EWM spectral profiles collected at three different sampling scales exhibit similar spectral signatures for our upper Great Lakes study areas?

The three data collection scales were individual SAV samples measured out of the water (sample footprint diameter $\sim 5 \mathrm{~cm}), \mathrm{SAV}$ in the water measured from a boat $(\sim 50 \mathrm{~cm})$, and SAV in the water measured from a UAS platform $(\sim 5 \mathrm{~m})$. If spectral signatures for SAV species appear distinct in one or more of these three levels of spectral profiling [out-of-water (OOW), boat side, and aerial UAS], then UAS-based high-resolution multispectral and hyperspectral sensing could become a practical tool for monitoring invasive SAV such as EWM.

\section{Sensing Design}

To address the study questions, we deployed and developed a set of remote sensing data collection tools that included spectroradiometers, natural color and multispectral cameras, and UAS to collect data at the three scales described above. The goal was to achieve species-level identification using spectroradiometers as a prerequisite for imaging SAV species of interest with multispectral cameras. This would enable mapping and monitoring of EWM versus non-EWM SAV species, with natural color digital cameras helping to identify and describe study areas along with providing a basemap for the multispectral results. We used an ASD Fieldspec 3 (Malvern Panalytical, Malvern, UK) for most OOW and boatside data collections using the software RS3. The ASD FieldSpec series of spectroradiometers have frequently been used for collecting spectral profiles of wetland vegetation species ${ }^{39,40}$ including SAV. ${ }^{41}$ For recent aquatic remote sensing research, colleagues at the Michigan Tech Research Institute (MTRI) developed a lightweight portable radiometer (LPR) system to enable spectroscopy at a lower cost and lighter weight than traditional handheld systems, such as the ASD FieldSpec $3 .{ }^{42}$ The LPR is compact and light enough to be flown onboard an UAS able to lift at least $1 \mathrm{~kg}$ and is housed in a plastic box that can be attached to a typical UAS payload platform. Initial field data in 2015 were collected using the first version of the LPR system, which integrated a global positioning system (GPS) receiver, a Raspberry Pi microcomputer for remote WiFi control of the system, a lithium ion battery, a skyward-facing Ocean Optics STS-VIS-RAD model spectrometer (a STS-VIS spectrometer with a range of 350 to $800 \mathrm{~nm}$ and a directly attached cosine corrector) to measure downwelling irradiance, two nadir-facing Ocean Optics spectrometers (one STS-UV/ultraviolet and one STS-NIR/near-infrared) with a combined spectral range of 190 to $1100 \mathrm{~nm}$, and a five megapixel (mp) Raspberry Pi camera for identification of the ground footprint captured by the nadir-facing spectrometers. The Ocean Optics STS sensors have been used by other authors for measuring water color ${ }^{30}$ and SAV reflectance. ${ }^{43}$ In 2016, field data were collected using LPR version 2, which replaced the UV and NIR nadir-pointing sensors with a single STS-VIS spectrometer with a range of 350 to $800 \mathrm{~nm}$ and a more compact data output format with improved metadata. In 2017, a third version of the LPR was used with similar sensors that covered through $1000 \mathrm{~nm}$. All STS series Ocean Optics spectrometers have a spectral resolution of $\sim 1.5 \mathrm{~nm}$ (FWHM) and a signal-to-noise ratio of greater than 1500:1. The integration time for a single measurement ranges from $10 \mu \mathrm{s}$ to $10 \mathrm{~s}$, making it possible to collect several spectra per UAS flight. The LPR and ASD FieldSpec were used as equivalent devices with calibration, as described in Sec. 3, except that the LPR could be mounted on a UAS platform for obtaining airborne spectral data. Recent work has shown that spectra collected with the 
LPR compared well to ASD data, ${ }^{44}$ with linear relationships with $R^{2}=0.941$ to 0.992 between ASD and LPR-derived spectra over the same locations. To enable the collection of boatside spectra that would be comparable to the UAS-based spectra, these were both collected at nadir to provide a similarly shaped circular footprint. We recognize that there are potential specular reflection issues with these nadir-collected spectra; however, previous studies have collected nadir spectra for shallow-water mapping. ${ }^{45,46}$

We used two multispectral camera systems in this study. We selected the MCA-6 six-channel multispectral camera manufactured by Tetracam (Chatsworth, California) for its ability to cover the 400 to $1000 \mathrm{~nm}$ (visible to near-infrared) spectral range, availability of different spectral filters within that range, and light weight $(<1 \mathrm{~kg}$ with battery). Each image channel has its own $1.3 \mathrm{mp}$ camera. The system was available for three 1-week data collection periods in 2016 and 2017. Standard Tetracam MCA-6 bands are $490 \mathrm{~nm}$ (blue), $550 \mathrm{~nm}$ (toward the upper range of green), $680 \mathrm{~nm}$ (red), $720 \mathrm{~nm}$ (red edge), $800 \mathrm{~nm}$ (in the near-infrared (NIR) range of $\sim 750$ to $1000 \mathrm{~nm}$ ), and $900 \mathrm{~nm}$ (also in the NIR). However, NIR wavelengths have limited penetration into water due to rapid light attenuation (i.e., strong absorption), ${ }^{47}$ and maximum penetration into water occurs at around the green wavelength of $530 \mathrm{~nm} .{ }^{48,49}$ Therefore, for the 2016 and 2017 data collections, the Tetracam manufacturer was able to change the wavelengths for two bands to better meet our study objectives of differentiating and mapping species of SAV. New selected wavelengths were $530 \mathrm{~nm}$ (near maximum light penetration) and $600 \mathrm{~nm}$ (orange) because preliminary 2015 spectral data had shown promising separation of some plant species at around $600 \mathrm{~nm}$. For 2016 and 2017, this made the available wavelengths $490 \mathrm{~nm}$ (blue), $530 \mathrm{~nm}$ (green 1), $550 \mathrm{~nm}$ (green 2), $600 \mathrm{~nm}$ (orange), $680 \mathrm{~nm}$ (red), and $720 \mathrm{~nm}$ (red edge).

As a low-cost multispectral backup, we developed a dual camera system, referred to as the VISNIR system, for the 2017 summer field season, that included a Canon point-and-shoot $16 \mathrm{mp}$ camera for natural color (RGB) data collection and a second Canon point-and-shoot camera modified to be sensitive only to the near-infrared range of $\sim 830$ to $1100 \mathrm{~nm}$. We deployed this dual system at the same time to collect visible plus near-infrared images, either on the UAS as described below or pole-mounted for high-resolution four-band imaging at a height of $\sim 3 \mathrm{~m}$.

We deployed a variety of UAS for the study, all of which met the US Federal Aviation Administration definition of a small UAS (under $25 \mathrm{~kg}$ ) and were flown by experienced UAS pilots. The largest system was a hexacopter (six rotors) system manufactured by Bergen RC Helicopters of Vandalia, Michigan. It had several important parameters, including being controllable remotely, capable of at least $15 \mathrm{~min}$ of flight time, having on-board position data from a GPS, a return to home default capability if the connection is lost, ability to fly a payload of up to $5 \mathrm{~kg}$, a tiltable sensor platform, and a reasonable cost (US $\$ 4,800$ ). It was capable of deploying the LPR as well as digital cameras up to the size of a Nikon full-frame camera and the multispectral cameras described above. The Bergen hexacopter's tiltable sensor platform enabled the LPR to face forward for takeoff but then be pointed nadir for spectral data collection. The Bergen hexacopter has frequently been used by the MTRI study team members as a reliable system for deploying a variety of airborne sensor systems. ${ }^{50}$ Upon initial testing, it was determined that for aquatic applications, the minimum flying height at which the downwash from the Bergen hexacopter does not disturb the water surface to a degree that interferes with spectra and imagery was $10 \mathrm{~m}$. Therefore, the minimum flying altitude of $\sim 10 \mathrm{~m}$ was used for collecting spectral data, and a height of $\sim 25 \mathrm{~m}$ was used for natural color image collection. Smaller DJI Phantom 2 Vision, Phantom 3 Advanced, and Mavic Pro quadcopter UAS were also used to provide rapid, lower resolution imagery of project areas.

Smaller UAS used in this project had their own integrated RGB camera systems with $12 \mathrm{mp}$. These were intended to provide sufficient detail to identify sites that might have EWM, to potentially map changes in overall SAV density, and most importantly, to provide orthophoto mosaic basemaps of the study areas. The $5 \mathrm{mp}$ camera onboard the LPR during UAS flights fulfilled a similar purpose. For higher resolution RGB imaging of study sites, our previous experience has shown that a Nikon D800 series DSLR camera can provide detailed digital images of ground features at flying heights of 10 to $30 \mathrm{~m},{ }^{50}$ so we deployed this system whenever possible to document study sites. 


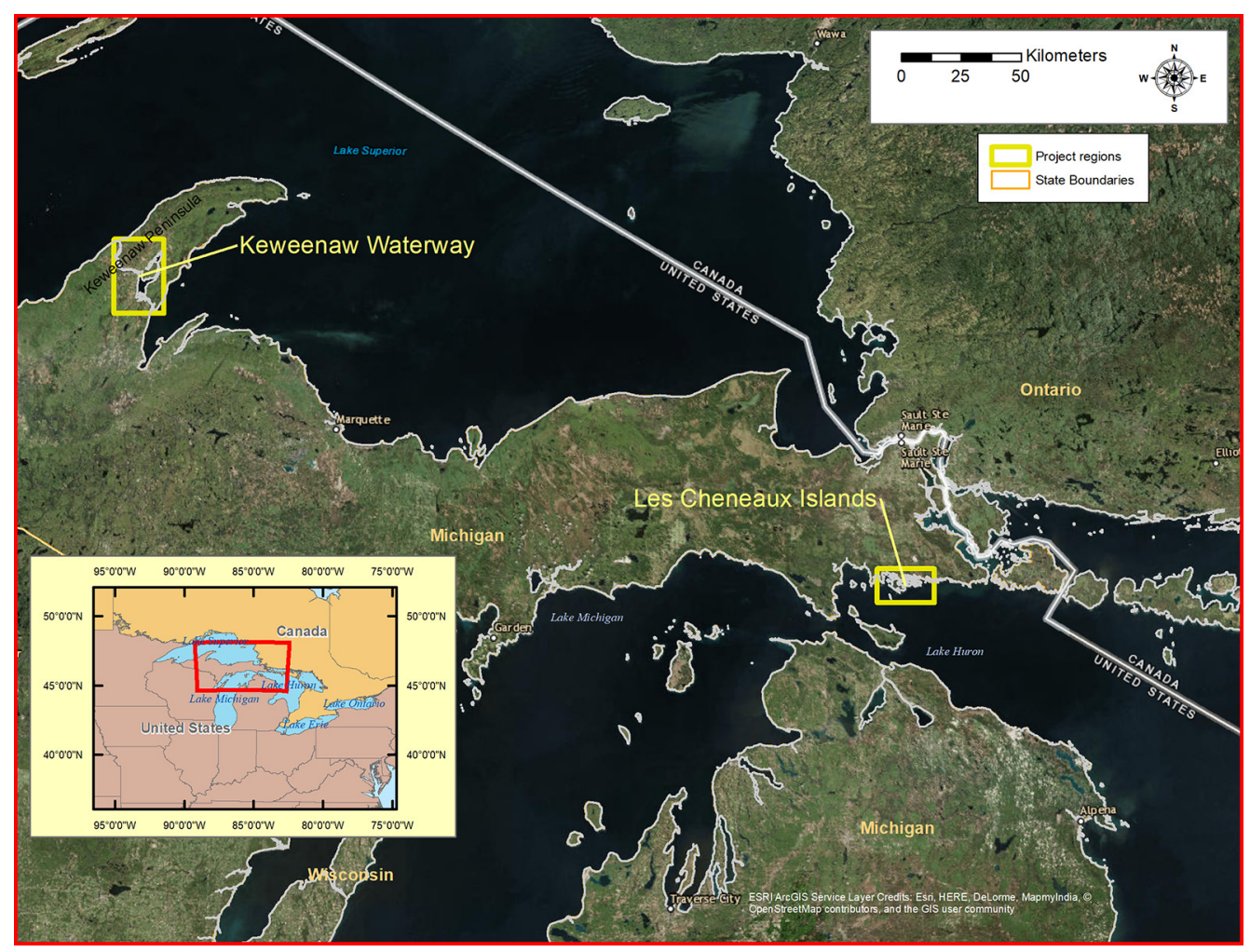

Fig. 1 Location of data collections in the Upper Peninsula of Michigan, including the Keweenaw Waterway in the Keweenaw Peninsula and the Les Cheneaux Islands area in northwest Lake Huron.

\section{Experiments and Validation}

\subsection{Data Collection Areas}

Study data characterizing the spectral profiles of vegetation from individual species to assemblages were collected at multiple sites in the Les Cheneaux Islands region of northwest Lake Huron (Figs. 1 and 2). EWM in Michigan and in other Midwestern states has been shown to mostly be hybrids of M. spicatum $\times$ Myriophyllum sibiricum (native Northern watermilfoil) and that where the hybrid was found, $M$. sibiricum was rare. ${ }^{51}$ We anticipated that most EWM in the Les Cheneaux Islands would be the hybrid form based on this and more recent studies. ${ }^{52}$ In 2015, data were collected at three sites located in the Keweenaw Waterway near Houghton, Michigan (Figs. 1 and 2) primarily to developed methods, such as the initial OOW data collection.

\subsection{Scales of Spectral Data Collection and Processing Methods}

To answer the study questions about EWM detection and spectral profile similarity, a diverse set of field spectra for EWM and other species and bottom types were needed. Table 1 lists all the sites, dates, number of averaged spectra by site, and scale of spectral data collections from 2015 to 2017. Species measured at each site on each date varied due to natural seasonal and interannual variability in the SAV assemblages growing at these sites at the time they were sampled, with several species occurring multiple times in the data collections, helping provide comparability among sites and data collection campaigns.

We recorded spectral data at three sampling levels:

1. Plant-level spectra of a single species of aquatic vegetation retrieved out of the water and sensed immediately after removal to prevent spectral decay with either the ASD FieldSpec 3 or the LPR system [Figs. 3(a) and 3(b)]. The spectrometer optic, with a 

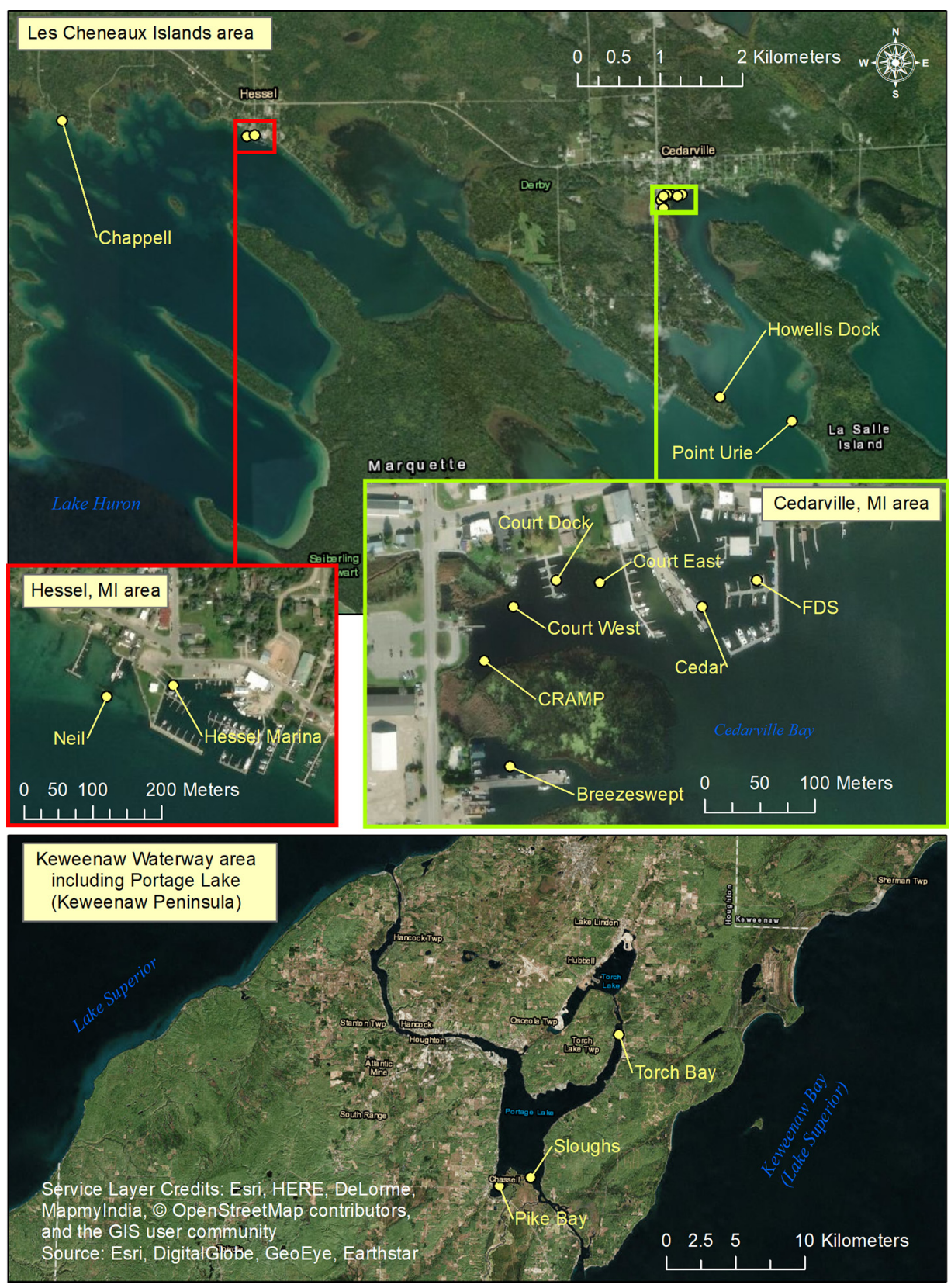

Fig. 2 Detailed locations of data collection sites for spectral and UAS data within the Les Cheneaux Islands and the Keweenaw Waterway.

$25 \mathrm{deg}$ FOV for either system, was held $\sim 10 \mathrm{~cm}$ above the plant surface for a sample footprint diameter of $\sim 5 \mathrm{~cm}$. Plant samples were large enough to occupy the entire footprint of the spectrometer at this distance, and the plant was piled in multiple layers and measured against a matte black tarp to minimize the spectral contribution of the background from any remaining small gaps between leaves. Visser et al ${ }^{53}$ and Vahtmäe and Kutser ${ }^{54}$ used very similar approaches of piling layers of aquatic vegetation on a black painted canvas and a black plastic bag, respectively, to obtain spectra without water column influences. These data represented the OOW scale and were intended to provide the strongest signal of plant spectra.

2. Spectral measurements were made from the side of the boat, with the sensor head mounted on an extension pole at least $1 \mathrm{~m}$ in length. The pole mount both allowed the operator to hold the sensor away from boat shadows and reflections and safely held the sensor at nadir. The spectra were also collected on the sunlit side of the boat to minimize 
Brooks et al.: Multiscale collection and analysis of submerged aquatic vegetation...

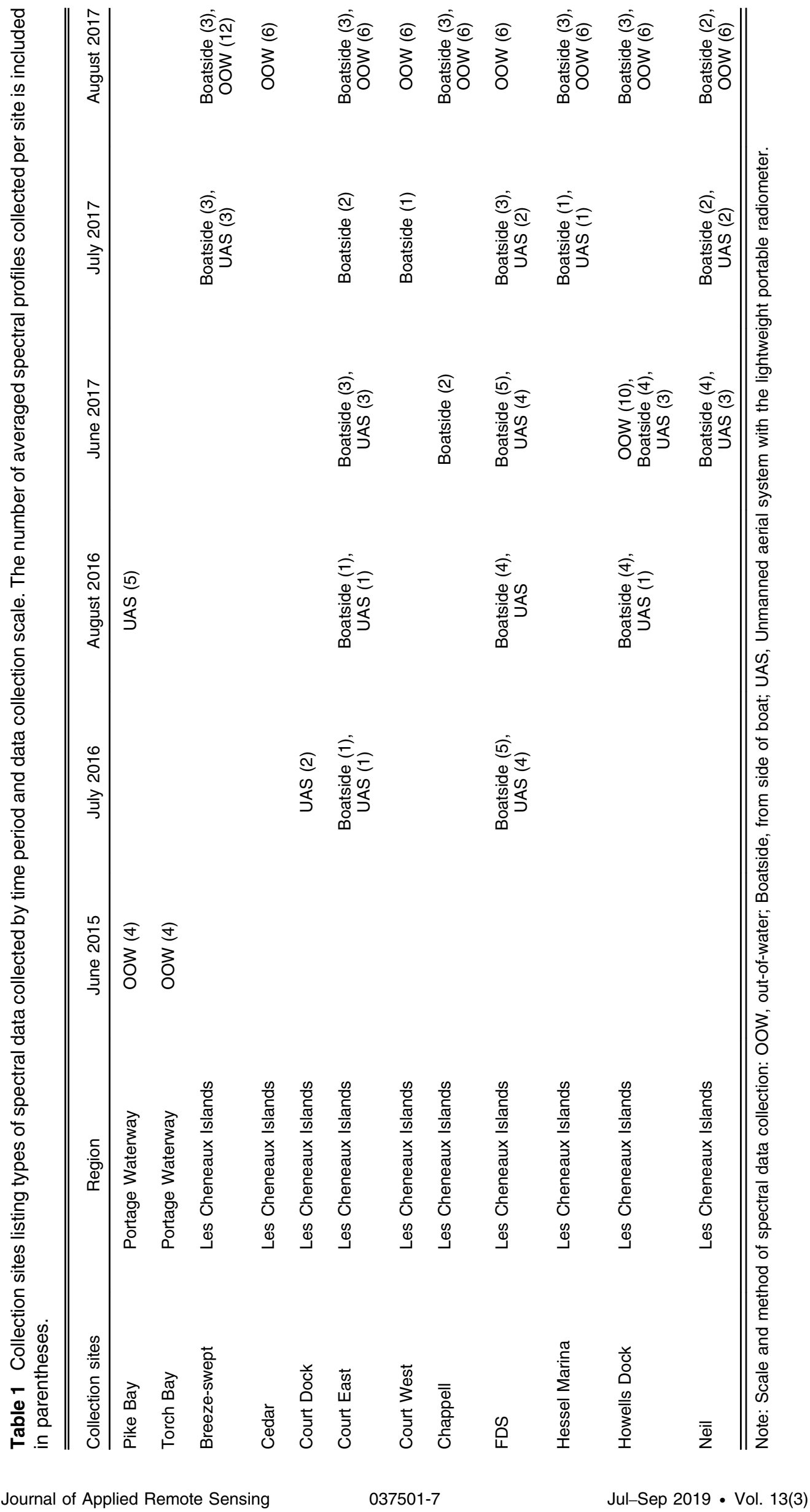




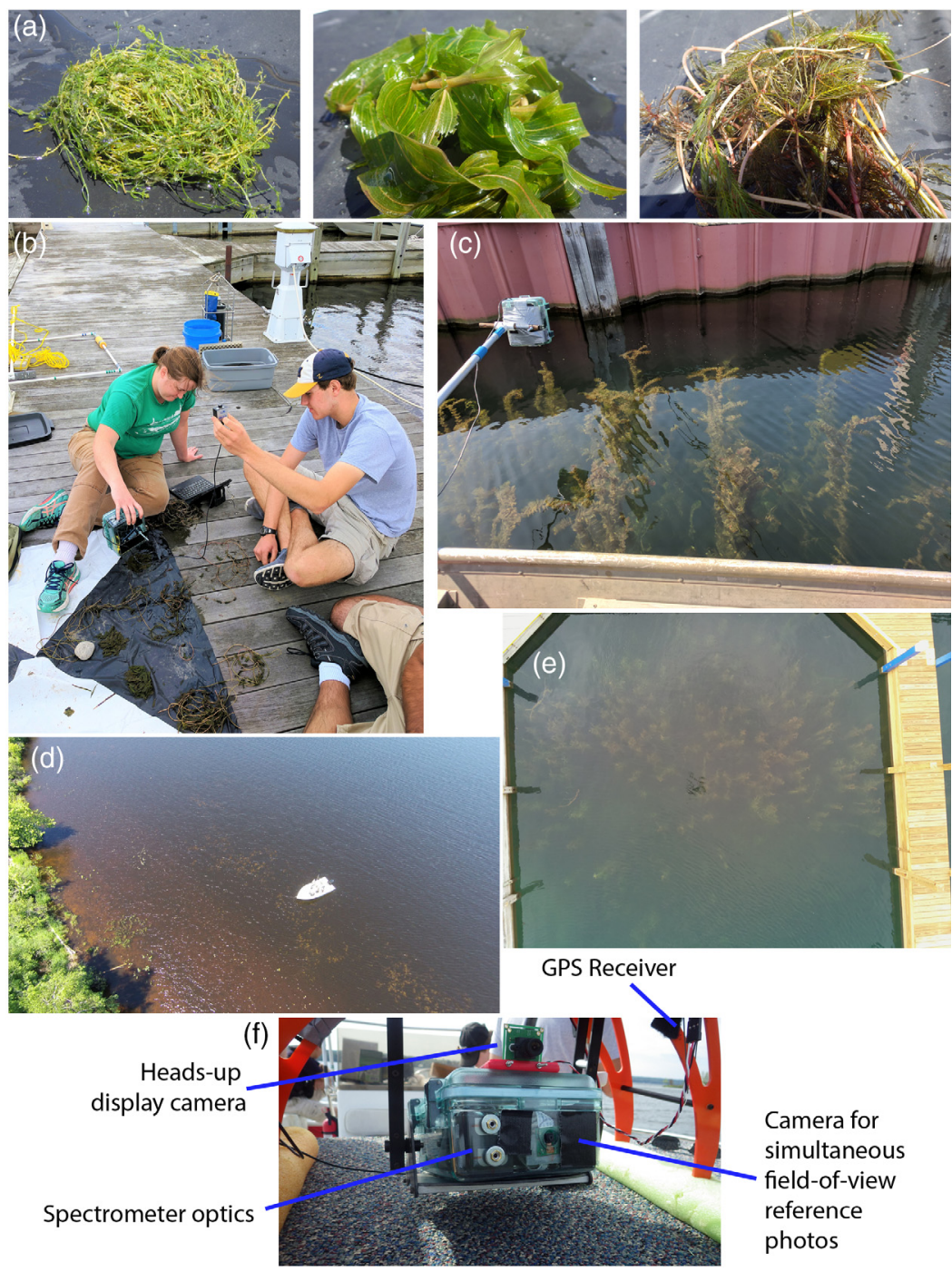

Fig. 3 Images demonstrating field data collection methods. (a) Single-species plants on a black tarp about to have their spectral profile recorded for OOW scale data. From left to right: Chara sp. (stonewort), Potamogeton richardsonii (clasping-leaf pondweed), and EWM. (b) Collection of OOW scale data using the LPR spectroradiometer during the August 2017 data collection. (c) Collection of spectral profile data at the boatside scale using the LPR spectroradiometer held vertically over an area of predominantly EWM. (d) Aerial photo from 2015 at a site in Keweenaw Waterway showing visible SAV, emergent vegetation, shoreline vegetation, and the Michigan Tech research vessel used for launch and recovery of the DJI Phantom 2 UAS. (e) Aerial photo taken from the Bergen hexacopter with the LPR's five mp camera, with EWM visible near the water's surface at a boat slip in the Hessel Marina site in the Les Cheneaux Islands study area. (f) The LPR mounted underneath the Bergen hexacopter UAS, about to collect spectral data over an area of EWM.

effects of light reflection from the boat or the boat shadow. Either spectrometer was used as available, with the optic held $\sim 1 \mathrm{~m}$ above the water surface immediately above a patch of vegetation for a spectra footprint radius at the water surface of $\sim 45 \mathrm{~cm}$ [Fig. 3(c)]. Spectral measurements were taken while keeping the boat stationary and visually confirming minimal disturbance of the water by the boat. Any measurements affected by disturbances such as accidental changes in sensor position or viewing geometry were noted and later removed from the dataset. Measurement locations were selected based on visual observation of the distribution of homogeneous patches of SAV species dominated by one to a few species. These data represented the "boatside" scale and would be similar to the traditional scale of vegetation sampling, such as rake tosses and twists. ${ }^{55}$ The 
spectra footprint radius could also represent a scale similar to aerial imagery collected via UAS.

3. Nadir spectra from the LPR system mounted on a UAS flying directly above a vegetation patch of known composition [Figs. 3(d)-3(f)]. When mounted on the UAS, the LPR's irradiance sensor was fixed to a rod on top of the system in the zenith direction so that there would be no shadowing. The UAS-based spectra were collected $\sim 10$ to $15 \mathrm{~m}$ above the water surface for a footprint radius at the water surface of 4.5 to $6.5 \mathrm{~m}$. These data represented the "LPR UAS" scale, referred to as just "UAS" in Table 1 and hereafter as the LPR that was the only radiometer that could flown in the UAS, and these data covered the largest area for spectral data collection.

The boat-based sampling was designed to test and demonstrate the strength of the spectral signature that could be expected to be available for UAS-based spectral profiling and imaging. This is a scale similar to the resolution of UAS-based multispectral imagery. If a strong vegetation spectral signature could be identified directly from the vegetation and from just above the water, then there would be a reasonable chance this could be captured with a UASbased spectrometer and with a multispectral imaging camera that captures relevant spectral wavelengths.

Analysis of the UAS-based spectra was designed to help understand whether vegetation types can be differentiated when a larger area is being assessed than the OOW or boatside scale data. With integration over the larger spectral footprint captured from the UAS platform, plant assemblages tended to include more than one SAV species. To address this issue, the sampling sites were summarized based on the two most dominant species if they made up at least $20 \%$ of the cover based on the visual estimate. For example, a site that had a visual estimate of 50\% EWM and $30 \%$ Elodea was summarized as an "EWM_ELODEA" spectral profile.

Visual estimates of plant species densities by percent were made by an experienced aquatic vegetation expert for areas where spectral data were being recorded, and species identities were confirmed by rake toss after spectral data collection was complete. These estimates were collected to document the dominant vegetation species that would be captured by the boatside and UAS-based spectral data collection. Specifically, for EWM plots, the average area covered by vegetation was $85.2 \%(\sigma=14.3 \%, n=25)$, the average for other SAV (SAV_OTHER) was $84.4 \%(\sigma=15.0 \%, n=14)$, for nonidentifiable low vegetation (LOWVEG), the average was $77.8 \%(\sigma=38.5 \%, n=4)$, the deepwater average (DEEPWATER) was $0.0 \%(\sigma=0.0 \%$, $n=3)$, and the bare average (BARE) was $33.1 \%(\sigma=17.2 \%, n=16)$.

All spectra were calibrated to remote sensing reflectance $\left(R_{\mathrm{rs}}\right)$, a unitless value defined as the ratio of water-leaving radiance to the total downwelling irradiance just above water. The ASD spectra were calibrated using a Spectralon panel of a known reflectance and the LPR spectra using a skyward-facing irradiance sensor (mounted on the UAS for airborne spectral data collections). The field spectra collected with the ASD FieldSpec3 and the LPR spectroradiometers were examined for data quality. Ten spectra were collected per target when using the ASD. Because it operates less rapidly, five spectra were collected per target when using the LPR to minimize the risk of the sensing platform drifting away from the target location. Outliers among spectra collected for the same target, indicating an effect of glint or other problems, were discarded. A calibration based on the differences between ASD and LPR spectra collected simultaneously for a Spectralon panel illuminated by a highly stable-lamp was applied to the radiance and irradiance values from the LPR spectrometers to make them comparable to ASD spectra, as used and described by Sawtell. ${ }^{42}$ This calibration was repeated at least once per field season to account for possible instrument drift over time. $R_{\mathrm{rS}}$ was calculated for ASD data using ViewSpec Pro software (Malvern Panalytical) and for LPR data as follows:

$R_{\mathrm{rs}}^{0+}=\frac{L_{w}^{0+}\left(\lambda, \theta_{\mathrm{d}}\right)}{E_{d}^{0+}(\lambda)}$

$=$ Water-leaving radiance just above the water surface/Downwelling irradiance,

Spectral profiles corresponding to the same sampling run at a particular location and target were averaged. 


\subsection{Statistical Analysis Methods}

To analyze whether spectral profiles were significantly different from each other for different species or assemblages, the averaged profiles were treated as distributions and analyzed using the nonparametric two-sample Kolmogorov-Smirnov (K-S) test (Sokal and Rohlf 1995) in $\mathrm{R}$ (versions 3.4.0 to 3.4.3; R Core Team 2017) with the ks.test command. The two sample $\mathrm{K}-\mathrm{S}$ test provides the ability to find out if two random variables share an identical distribution or if they come from different distributions. ${ }^{56,57}$

The K-S test analysis focused on the spectral reflectance data for the OOW species-level samples, collected in 2017 and 2015 using the ASD FieldSpec3 spectroradiometer because the differences among species should be strongest in this dataset. A sample of the 2016 boatside data was also analyzed for all bands. To understand whether small variations in spectral responses captured by using all spectral bands were potentially causing the application of the K-S test to not recognize when the profiles were very similar, band averaging was applied to reduce the dataset. These would also simulate the results of using imaging systems with fewer bands that could be practical to deploy, such as hyperspectral and multispectral sensors. Three levels of averaging were analyzed:

1. The same six bands as the Tetracam multispectral camera. These represented averaging of 10 one-nm-wide bands (i.e., $490 \mathrm{~nm}$ is an average of the reflectance values of 485 to $495 \mathrm{~nm}$, etc.). Although such average reflectances may not measure the "true" reflectances that the Tetracam would measure, they provide a good approximation for the reflectance in the Tetracam wave bands, as Tetracam spectral response functions were not available to us. If the Tetracam-like reflectance values for the various SAV species in the spectroradiometer datasets looked significantly different, this would bolster the case that multispectral imaging could reliably differentiate EWM from other aquatic vegetation.

2. The eight spectral bands that contain most of the spectral information needed to map coastal wetlands in the Great Lakes including SAV, according to Becker et al., ${ }^{58,59}$ which were (rounded to the nearest nm) $515 \mathrm{~nm}$ (green), $560 \mathrm{~nm}$ (green), $686 \mathrm{~nm}$ (red), and $732 \mathrm{~nm}$ (red edge), plus the near-infrared bands of 812, 824, 836, and $940 \mathrm{~nm}$. The 2015 and 2017 OOW data were averaged to 10-nm bands centered around each of these, which will hereafter be referred to as "Becker bands." These bands were tested to see if they provided sufficient spectral information for species differentiation of SAV in our study area.

3. To test the effect of the number of bands on the separability of spectral signatures, the 651 individual spectral bands were averaged into 65 10-nm-wide bands; Everitt et al. ${ }^{36}$ used $10-\mathrm{nm}$ wide bands for their tank-based spectral analysis of SAV. The 10 -nm-wide bands covered the individual bands from 350 to $1000 \mathrm{~nm}$ (350-359 nm, 360-369 nm, etc; $1000 \mathrm{~nm}$ was not included to make the 65 bands evenly sized). Testing 65 bands was also more representative of hyperspectral imaging systems that could be deployed than using all 651 bands. The June 2017 OOW dataset was used for this test as it had more SAV vegetation types for evaluating EWM detection versus other species.

To test for the capability of indices and ratios to help differentiate SAV species when combined with reduced datasets, the following indices were calculated as described below:

- Red edge/blue ratio (RE/BLUE, i.e., $720 \mathrm{~nm} / 490 \mathrm{~nm}$ )

- The modified normalized difference vegetation index (mNDVI)

- The modified normalized difference aquatic vegetation index (mNDAVI)

- The modified water-adjusted vegetation index (mWAVI).

NDVI, NDAVI, and WAVI were previously developed for terrestrial (NDVI) or aquatic uses (NDAVI and WAVI) but were included because of the possibility that sufficient light penetration might enable them to be useful for mapping SAV near the water's surface.

The red edge/blue (RE/BLUE) ratio was selected from among several tested ratios [red edge to red $(720: 680 \mathrm{~nm})$, red edge to orange $(720: 600 \mathrm{~nm})$, red edge to green $2(720: 550 \mathrm{~nm})$, and red 
edge to green $1(720: 530 \mathrm{~nm})$ ] based on it having the largest standard deviation for the dominant vegetation types in the June 2017 OOW data and therefore providing the greatest potential for it to differentiate SAV types.

NDVI is a long-used indicator of green biomass, with larger values indicating more green biomass being present. ${ }^{60,61}$ Here, the $720-\mathrm{nm}$ red edge band was used in place of the NIR band for analysis, as it was the longest wavelength collected with the Tetracam system that was used for SAV mapping. Thus, the modified NDVI has the following formula, where $\rho$ is the wavelength:

$$
\text { mNDVI }=\frac{(\rho \text { RedEdge }-\rho \text { Red })}{(\rho \text { RedEdge }+\rho \text { Red })}
$$

Previous work has found red-edge reflectance to be useful for identifying wetland vegetation types due to its sensitivity to biomass. ${ }^{15,62}$ The nearby red edge wavelength of $715 \mathrm{~nm}$ has also been shown to have a strong relationship with leaf area index (LAI) for SAV. ${ }^{43}$

As NDVI was developed as an index for terrestrial biomass analysis, two related aquatic indices reviewed and used by Villa et al. ${ }^{63}$ that might help with SAV mapping were also modified for application here: the NDAVI and WAVI. NDAVI uses a blue band instead of a red band in the NDVI formula. Again, we used the 720-nm red edge band in place of an NIR band, yielding the following formula:

$$
\operatorname{mNDAVI}=\frac{\rho_{\text {RedEdge }}-\rho_{\text {BLUE }}}{\rho_{\text {RedEdge }}+\rho_{\text {BLUE }}} .
$$

WAVI also uses a blue band instead of red but also includes a correction factor $(L)$ to adjust for the effect of the background signal. We adopted a value of 0.5 for $L$ based on Villa's description of this as a reasonable value for reducing background influence. The formula for mWAVI is as follows:

$$
\text { mWAVI }=(1+L) \frac{\rho_{\text {RedEdge }}-\rho_{\text {BLUE }}}{\rho_{\text {RedEdge }}+\rho_{\text {BLUE }+L}} .
$$

We compared spectral characteristics among plots with differing SAV cover using analysis of variance (ANOVA) using the larger set of boatside data, which totaled 62 spectral data profiles, covering data collections in mid-July 2016, late August 2016, late June 2017, mid-July 2017, and late August 2017. A dominant vegetation type was selected for each of the 62 spectral profiles based on density at each location, resulting in 12 vegetation types. These vegetation types were summarized by dominant vegetation type to help differentiate EWM from other spectral patterns with the month of data collection included. The values of the six Tetracam bands $(490,530,550,600,680$, and $720 \mathrm{~nm})$, the RE/BLUE ratio, and the three indices (mNDVI, mNDAVI, and mWAVI) were compared between plots with different dominant plant covers.

To determine whether EWM was generally different from any other sampled SAV type, the other SAV dominant vegetation types were grouped into an "other SAV" class. These dominant vegetation groups were tested with study dates using two-way ANOVA, with plots nested within study areas as a random factor. The classes considered were: DOMVEG_GRP, which included the spectral vegetation profiles grouped in to one representing EWM, the one for all other SAV vegetation types (SAV_OTHER), one for areas of short vegetation at the lake bottom that was not identifiable by species (LOWVEG), areas of deepwater (DEEPWATER), or bare bottom types such as sand or rock (BARE) categories. All two-way ANOVA analyses were conducted using PROC MIXED in SAS version 9.4 (SAS Institute, Inc., Cary, North Carolina), and significance was considered at $p=0.05$. The six Tetracam band wavelengths (averaged from 10-nm wide) were log-transformed to meet assumptions of normal residual distribution and constant variance ${ }^{64}$ all other variables except mWAVI did not require transformation to meet these ANOVA assumptions. mWAVI included negative values and was log-transformed after adding a small value to make them positive. The interaction between DOMVEG_GRP and month (DOMVEG_GRP*MONTH) was included in the ANOVA analysis. 
To evaluate the impact of the three different scales of collecting spectral data, EWM spectral profiles were compared from the June 2017 data collection when OOW, boatside, and LPR UAS data were collected at the same sites on the same day. A single-factor ANOVA was applied to each band, ratio, and index to evaluate if any of the means were significantly different. Input values were transformed in the same way as the multiyear boatside ANOVA. If the ANOVA indicated that at least one group mean was different at the $p=0.05$ level based on spectral data collection method, then Tukey's honestly significant difference (TukeyHSD) test and the Tukey-Kruskal test were applied to see which group mean pairings were different (UAS versus BOATSIDE, OOW versus BOATSIDE, and OOW versus UAS). The TukeyHSD, also known as the Tukey-Kramer method, is for performing multiple pairwise comparisons between all group means. ${ }^{65}$ While it can be used when sample sizes are different for groups being tested, this makes it conservative (i.e., harder to reject the null hypothesis of no difference in group means). ${ }^{65}$ To account for this, the Tukey-Kruskal procedure was used, which performs a version of TukeyHSD procedure that works for unequal sample sizes. ${ }^{66}$ These tests were performed in R.

\section{Results and Discussions}

\subsection{Out-of-Water Spectral Data Results}

To first address the question of whether different SAV species appear spectrally different, we compared OOW spectral profiles. For 2015 to 2017, we collected a total of 78 OOW spectral profiles after averaging. The June 2015 OOW spectral data, collected at the Pike Bay study area, included one sample each of Nymphaea odorata (white water-lily), Vallisneria americana (eel grass), Potamogeton richardsonii (clasping-leaf pondweed), Nuphar advena (spatterdock), Certophyllum demersum (coontail), Sparganium fluctuans (floating bur-reed), Elodea canadensis (common waterweed), and EWM. The OOW spectral reflectance data for June 2017 were collected at the Howells Dock study area in the Les Cheneaux Islands and included profiles for two EWM samples, and one each of Potamogeton robbinsii (fern-leaf pondweed or Robbins' pondweed), Potamogeton richardsonii (clasping-leaf pondweed), Chara spp. (muskgrass), M. sibiricum (northern watermilfoil), Potamogeton praelongus (white-stemmed pondweed), and Potamogeton gramineus (variable-leaf pondweed), plus a matte black background tarp for reference.

Figures 4(a) and 4(b) show examples of OOW spectral data from 350 to $1000 \mathrm{~nm}$ collected with the ASD Fieldspec 3. Applying the K-S test to these datasets, the EWM OOW sample from 2015 was significantly different than all other vegetation types when using all 651 spectral bands at the $p<0.001$ level. Similarly, both 2017 EWM spectral samples [EWM1 and EWM2 in Fig. 4(b)] were also significantly different than all other vegetation types and each other, at the $p<0.001$ level.

For the June 2015 dataset resampled to the Tetracam bands [Fig. 5(a)], the EWM sample was significantly different $(p<0.05)$ from the spatterdock and floating bur-reed spectral samples but not the white water-lily, eel grass, clasping-leaf pondweed, coontail, or Elodea samples. Using the Becker bands [Fig. 5(b)], the EWM sample was not significantly different than any of the other species at the $p<0.05$ level. In Figs. 5(a) and 5(c), the $720 \mathrm{~nm}$ (red edge) band provides the greatest variation in spectral response. In Figs. 5(b) and 5(d), all of the Becker NIR bands $(732,812,824,836$, and $940 \mathrm{~nm})$ show relatively clear separation of sampled species.

Using the June 2017 OOW spectral data resampled to the Tetracam bands [Fig. 5(c)], the two EWM samples only differed significantly from the black reference tarp using the K-S test $(p=0.05)$. They were not significantly different from the curly-leaf pondweed, fern-leaf pondweed, clasping-leaf pondweed, Chara spp., native northern watermilfoil, white-stemmed pondweed, and variable-leaf pondweed spectral samples. There appear to be some groupings at 530 and $550 \mathrm{~nm}$ (the two green bands), with the white-stemmed pondweed, clasping-leaf pondweed, variable-leaf pondweed, and Chara spectral samples grouping together at higher green values, whereas the two EWM samples (EWM1 and EWM2), curly-leaf pondweed, northern watermilfoil, and fern-leaf pondweed spectral samples group together at lower green reflectance values. Similar to the 2015 data, there is a greater differentiation among species with the $720 \mathrm{~nm}$ (red edge) band [Fig. 5(c)]. The same June 2017 OOW dataset resampled to the eight Becker 
Brooks et al.: Multiscale collection and analysis of submerged aquatic vegetation...

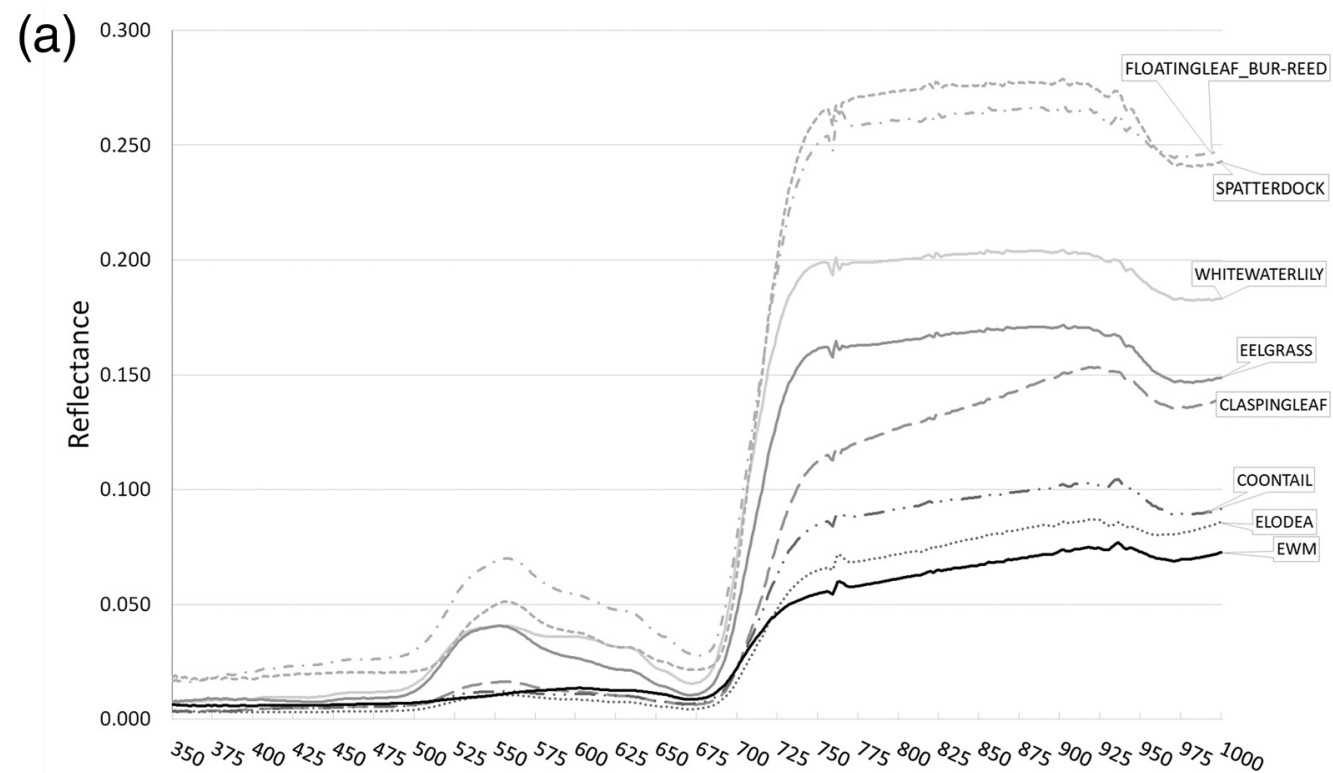

(b) 0.200

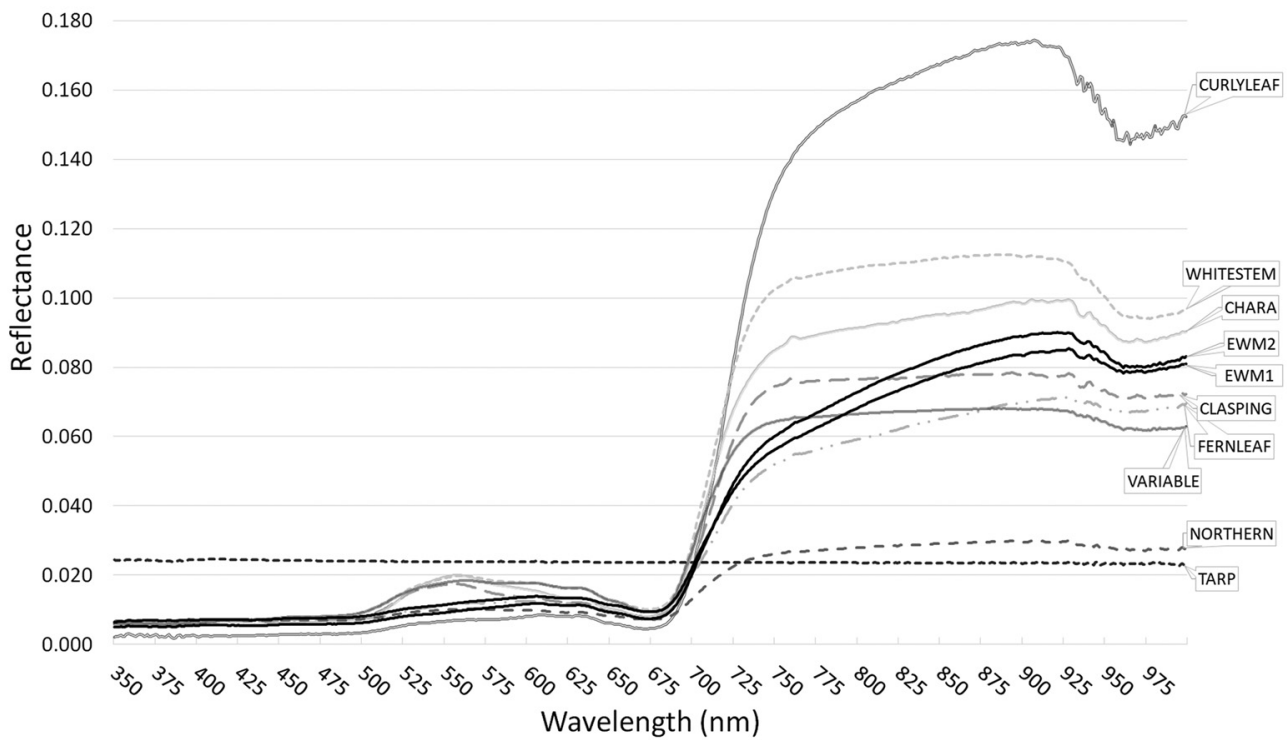

Fig. 4 OOW spectral data: (a) Spectral profiles of eight OOW aquatic plant species from June 2015, showing ultraviolet to near-infrared (350 to $1000 \mathrm{~nm}$ ) wavelengths for all 651 bands. (b) Spectral profiles for nine aquatic plant species, plus a reference tarp, from June 2017, showing all 651 one-nm wide bands.

wetlands bands [Fig. 5(d)] also did not result in significant differences when comparing the two EWM samples to the other vegetation types using the K-S test. The same groupings occur as in the Tetracam bands, with white-stemmed pondweed, clasping-leaf pondweed, variable-leaf pondweed, and Chara having higher $560 \mathrm{~nm}$ (green) reflectance values, and curly-leaf, both EWM samples, northern watermilfoil, and fern-leaf having lower $560 \mathrm{~nm}$ values. There is a greater separation between values at the Becker red edge bands (centered at $732 \mathrm{~nm}$ rather than the Tetracam's 720-nm red edge wavelength).

Using 65 bands and the June 2017 OOW, ASD-collected dataset yielded the K-S results shown in Table 2.

This analysis suggested that EWM1 was significantly different from six of the seven other SAV species, the other EWM sample (EWM2), and a black reference tarp, with varying levels of significance. EWM1 was not significantly different from the Clasping-leaf pondweed. EWM2 

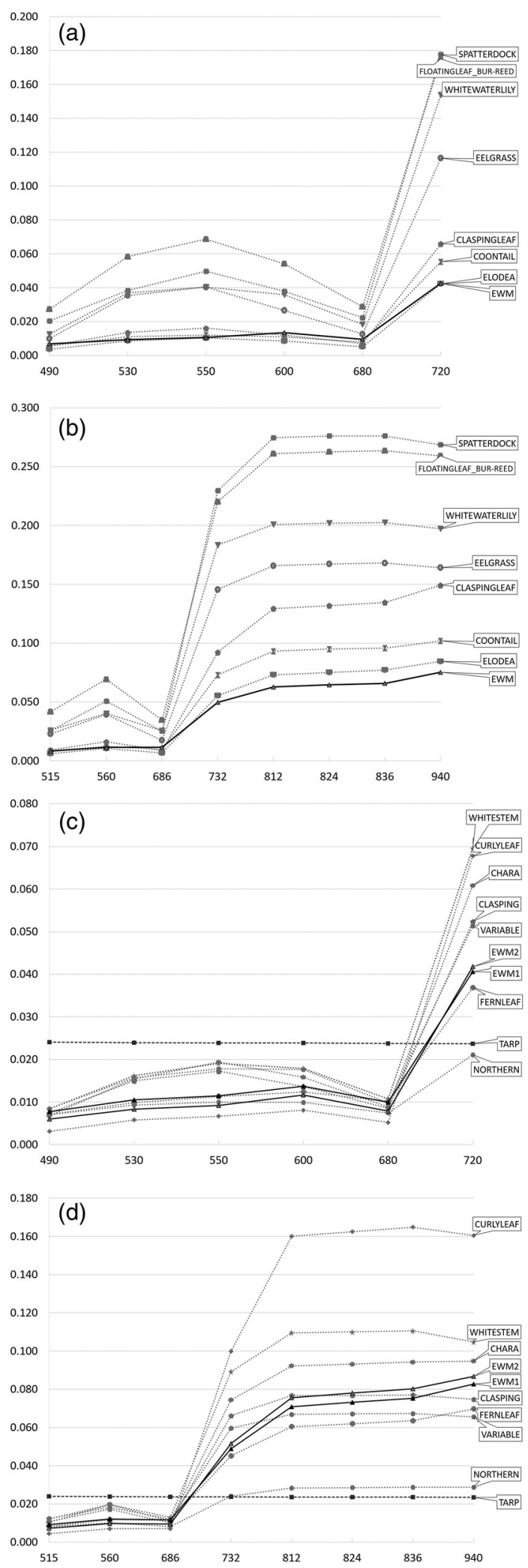

Fig. 5 Resampled spectral reflectance values for Tetracam and Becker bands: (a) Resampled to approximate the Tetracam bands for the eight OOW species samples collected in 2015, (b) resampled to the Becker bands for the 2015 OOW data, (c) spectral reflectance values for the Tetracam wavelengths for the nine OOW species collected in June 2017, and (d) spectral reflectance values for the Becker wetland bands for the nine OOW species collected in June 2017. 
Brooks et al.: Multiscale collection and analysis of submerged aquatic vegetation...

Table 2 K-S test of June 2017 OOW spectral data averaged to 65 10-nm-wide bands.

\begin{tabular}{llcccccccc}
\hline \hline $\begin{array}{l}\text { Tested } \\
\text { profile }\end{array}$ & Species profile & $p$-Value & $D$ & profile & Species profile & $p$-Value & $D$ & \\
\hline EWM1 vs & CURLYLEA & 0.0000209 & 0.4 & $* * *$ & EWM2 vs & CURLYLEAF & 0.0000209 & 0.4 & $* * *$ \\
& FERNLEAF & 0.00746 & 0.3 & $* *$ & & FERNLEAF & 0.00211 & 0.3 & $* *$ \\
& EWM2 & 0.03858 & 0.2 & $*$ & & EWM1 & 0.03858 & 0.2 & $*$ \\
& CLASPING & 0.0625 & 0.20 & & CLASPING & 0.0133 & 0.3 & $*$ \\
& CHARA & 0.0001122 & 0.45 & $* * *$ & & CHARA & 0.0133 & 0.3 & $*$ \\
& NORTHERN & 0.00000336 & 0.4 & $*$ & & NORTHERN & 0.00000336 & 0.4 & $* * *$ \\
& WHITESTEM & 0.0000209 & 0.4 & $* * *$ & & WHITESTEM & 0.0000209 & 0.4 & $* * *$ \\
& VARIABLE & 0.004037 & 0.3 & $* *$ & & VARIABLE & 0.00107 & 0.3 & $* *$ \\
& TARP & $<0.0000001$ & 0.5 & $* * *$ & & TARP & $<0.0000001$ & 0.5 & $* * *$ \\
\hline \hline
\end{tabular}

*Significant at $p<0.05$

${ }^{* *}$ Significant at $p<0.01$.

${ }^{\star \star \star}$ Significant at $p<0.001$.

was different from all seven vegetation species and the reference tarp. With both EWM samples being different than nearly all other vegetation samples, this supports the idea that hyperspectral sensing with a number of bands of similar to the 65 average bands tested here may be a reliable way of identifying SAV to species, including invasive aquatic plants such as EWM.

\subsection{Boatside Spectral Data Results}

Figure 6 represents boatside spectral data collected at three locations in the Les Cheneaux Islands study location in August 2016, a part of the 62 total spectral profiles collected in 2016 to 2017. The site with mostly bare rock beneath the ASD had higher reflectance than the vegetated areas,

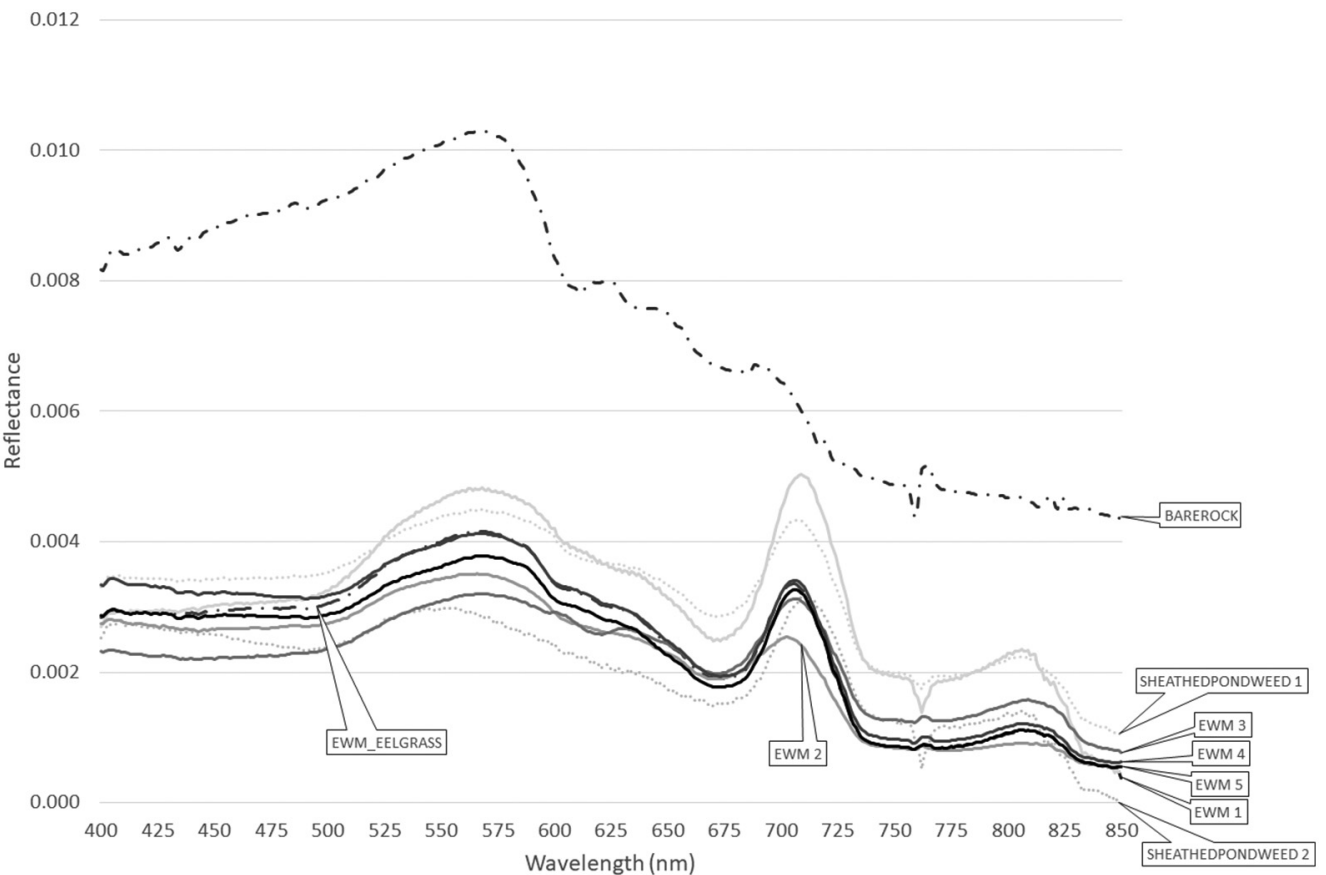

Fig. 6 Spectral profiles of SAV species and combinations from 2016, collected boatside using the ASD, directly over patches of vegetation in the water. 
as would be expected. Vegetation types were either mostly EWM (EWM1, EWM2, EWM3, EWM4, and EWM5), a mixture of EWM and eel grass (EWMEELGRASS), or mostly sheathed pondweed (SHEATHEDPONDWEED1 and SHEATHEDPONDWEED2). In all cases, the August 2016 boatside spectral profiles were different from all other spectral profiles at $p<0.001$ when using all collected bands.

The results of the two-way ANOVA mixed model analysis of the combined 2016 to 2017 boatside spectral dataset are shown in Table 3 .

Table 3 Results for the mixed model analysis for each tested wavelength, ratio, and index for the complete 2016 to 2017 boatside dataset with 62 spectral profiles.

\begin{tabular}{|c|c|c|c|c|c|c|}
\hline \multicolumn{7}{|c|}{ Dependent variable } \\
\hline & Effect & Num DF & Den DF & $F$ value & $\operatorname{Pr}>F$ & \\
\hline \multirow[t]{3}{*}{$490 \mathrm{~nm}$} & DOMVEG_GRP & 4 & 15.7 & 1.26 & 0.3285 & \\
\hline & MONTH & 2 & 10.6 & 5.53 & 0.0227 & * \\
\hline & DOMVEG_GRP*MONTH & 4 & 9.52 & 1.91 & 0.1888 & \\
\hline \multirow[t]{3}{*}{$530 \mathrm{~nm}$} & DOMVEG_GRP & 4 & 15.3 & 1.22 & 0.3422 & \\
\hline & MONTH & 2 & 10.5 & 6.68 & 0.0135 & * \\
\hline & DOMVEG_GRP*MONTH & 4 & 9.32 & 1.58 & 0.2576 & \\
\hline \multirow[t]{3}{*}{$550 \mathrm{~nm}$} & DOMVEG_GRP & 4 & 15.2 & 1.17 & 0.3637 & \\
\hline & MONTH & 2 & 10.3 & 7.63 & 0.0093 & * \\
\hline & DOMVEG_GRP*MONTH & 4 & 9.09 & 1.47 & 0.2873 & \\
\hline \multirow[t]{3}{*}{$600 \mathrm{~nm}$} & DOMVEG_GRP & 4 & 15.5 & 0.83 & 0.5235 & \\
\hline & MONTH & 2 & 10.1 & 6.8 & 0.0135 & * \\
\hline & DOMVEG_GRP*MONTH & 4 & 8.61 & 1.78 & 0.2198 & \\
\hline \multirow[t]{3}{*}{$680 \mathrm{~nm}$} & DOMVEG_GRP & 4 & 15.9 & 0.64 & 0.6406 & \\
\hline & MONTH & 2 & 9.87 & 4.33 & 0.0446 & * \\
\hline & DOMVEG_GRP*MONTH & 4 & 8.65 & 2.31 & 0.1396 & \\
\hline \multirow[t]{3}{*}{$720 \mathrm{~nm}$} & DOMVEG_GRP & 4 & 15.9 & 0.54 & 0.7055 & \\
\hline & MONTH & 2 & 8.44 & 2.99 & 0.1044 & \\
\hline & DOMVEG_GRP*MONTH & 4 & 6.96 & 2.86 & 0.1072 & \\
\hline \multirow[t]{3}{*}{ RE/BLUE } & DOMVEG_GRP & 4 & 18.6 & 1.22 & 0.3344 & \\
\hline & MONTH & 2 & 18.2 & 0.07 & 0.9348 & \\
\hline & DOMVEG_GRP*MONTH & 4 & 18.0 & 0.90 & 0.4839 & \\
\hline \multirow[t]{3}{*}{ mNDVI } & DOMVEG_GRP & 4 & 17.5 & 3.16 & 0.0402 & * \\
\hline & MONTH & 2 & 17.1 & 1.54 & 0.0135 & \\
\hline & DOMVEG_GRP*MONTH & 4 & 17.0 & 2.00 & 0.2198 & \\
\hline \multirow[t]{3}{*}{ mNDAVI } & DOMVEG_GRP & 4 & 14.9 & 1.35 & 0.2961 & \\
\hline & MONTH & 2 & 15.1 & 0.47 & 0.6358 & \\
\hline & DOMVEG_GRP*MONTH & 4 & 14.9 & 0.77 & 0.5586 & \\
\hline \multirow[t]{3}{*}{ mWAVI } & DOMVEG_GRP & 4 & 23.2 & 0.97 & 0.4415 & \\
\hline & MONTH & 2 & 22.7 & 0.42 & 0.6623 & \\
\hline & DOMVEG_GRP*MONTH & 4 & 22.7 & 0.21 & 0.9319 & \\
\hline
\end{tabular}

*Significant at the $p=0.05$ level. 
mNDVI was significantly different among dominant vegetation groups $\left(F_{4,17.5}=3.16\right.$, $p=0.04$ ), with no difference among months and no significant interaction between month and dominant vegetation group. The RE/BLUE ratio, mNDAVI, and mWAVI did not have significant differences among dominant vegetation groups or months and had no significant interactions between month and dominant vegetation group. The log-transformed 490-, 530-, 550-, 600-, and 680-nm variables varied significantly among months, but $720 \mathrm{~nm}$ did not, showing that there is an effect on spectral reflectance depending on whether data were collected in June, July, or August.

To help verify a significant contribution of vegetation to these boatside spectra, we calculated the difference between red edge reflectance $(709 \mathrm{~nm})$ in our spectra and a baseline between 681 and $754 \mathrm{~nm}$, analogous to the MERIS maximum chlorophyll index (MCI) product developed by Gower et al. ${ }^{67}$ Since our original classification considered all plots with up to $50 \%$ vegetation cover to belong to the "BARE" class, we also added an additional class of sparse vegetation, "SPARSEVEG," with vegetation percent cover of $25 \%$ to $50 \%$. With this "mixed" class added, we found a distinct difference in MCI values between the EWM and SAV_OTHER classes versus the lower MCI values of the BARE, LOWVEG, and DEEPWATER classes. The mean values, with standard deviations in parentheses, are SAV OTHER $=0.0012901$ $(\sigma=0.0014205), \mathrm{EWM}=0.0012412(\sigma=0.0017040), \mathrm{BARE}=-0.0000027(\sigma=0.0000932)$, SPARSE VEG $=0.0003125(\sigma=0.0003066)$, LOW VEG $=-0.0000606(\sigma=0.0001971)$, and DEEP WATER $=-0.0001423(\sigma=0.0001133)$

\subsection{UAS Spectral Data Results}

Figure 7 shows the complete spectral profiles for the June 2017 UAS data, a part of the 41 total UAS-based spectral profiles collected in 2016 to 2017. The six Tetracam bands were again approximated from the profile data, and the four ratios were added for analysis with the $\mathrm{K}-\mathrm{S}$ test.

The June 2017 UAS-based data (Fig. 7 and Table 4) showed that the six samples including significant EWM cover (five with EWM being the most dominant and one dominated by Chara with EWM as a secondary dominant) did appear statistically different than some other vegetation types. For example, the "EWM_SMALL1" (EWM and small-leaf pondweed)

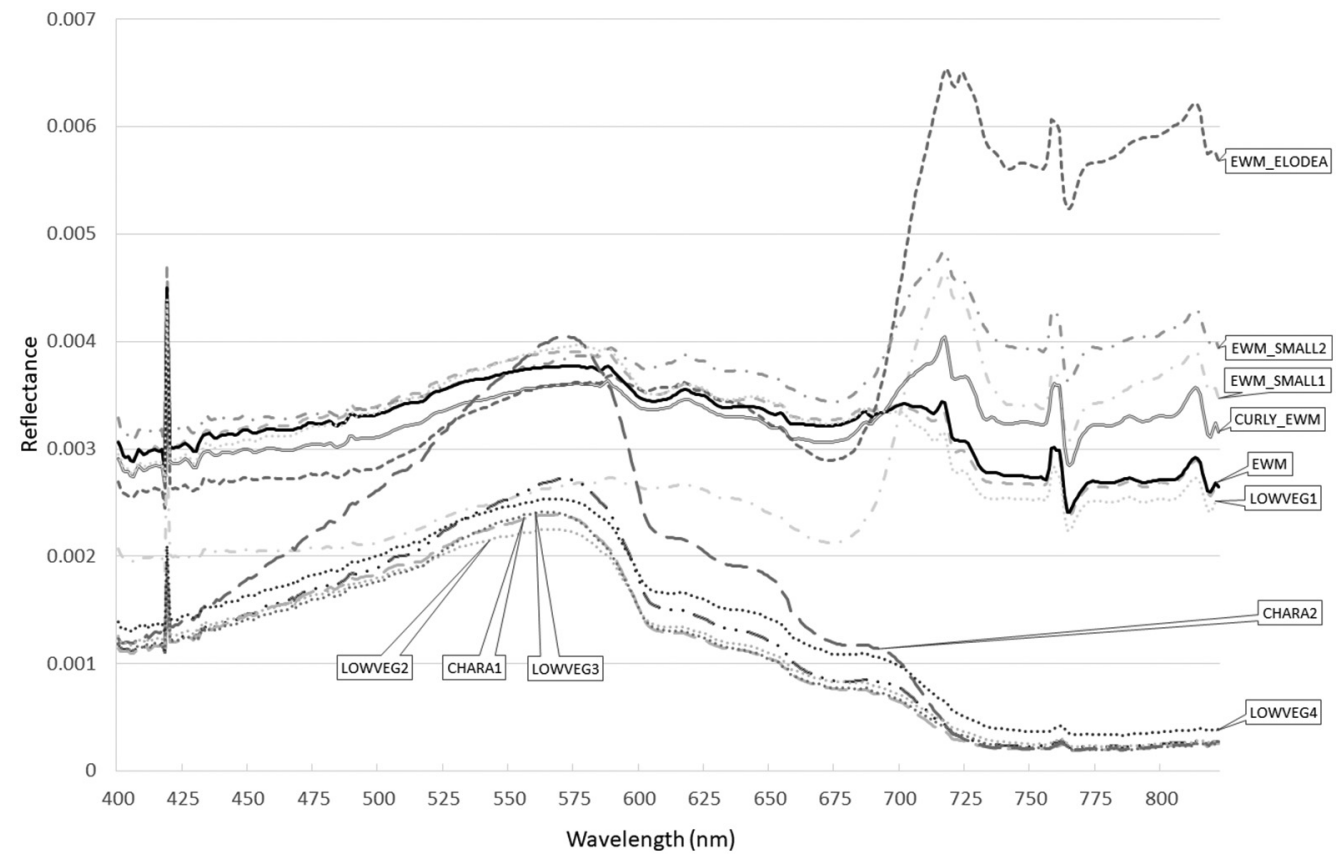

Fig. 7 Spectral reflectance values for the UAS data collected over 13 areas with multiple species assemblages, sampled in June 2017. 
sample is significantly different than one of the two Chara-dominated spectral profiles, and the EWM_CHARA and LOWVEG2 to LOWVEG4 profiles as well. The EWM_SMALL2, EWM_ELODEA, and CURLY_EWM profiles had similar results-they looked different than the two CHARA profiles, the EWM_CHARA, and LOWVEG2 to LOWVEG4 profiles. The EWM spectral profile without a secondary dominant species (EWM) was only different than the second (CHARA2) profile, however. All the "top" spectral data in Figure 7 (EWM_ELODEA to LOWVEG1) had to be collected on 2 days when it was $100 \%$ overcast. The "bottom" spectral data in Fig. 7 (CHARA2, LOWVEG2, CHARA1, LOWVEG3, and LOWVEG4) were from days when it was $40 \%$ to $60 \%$ cloud cover. There does appear to be an influence of sky conditions here, but with replication already a challenge, we preferred to maintain data whenever possible.

Table 4 K-S test of June 2017 UAS-based spectral data resampled to Tetracam bands plus ratios.

\begin{tabular}{|c|c|c|c|c|c|c|c|}
\hline $\begin{array}{l}\text { Tested } \\
\text { profile }\end{array}$ & Species profile & $p$-Value & $D$ & $\begin{array}{l}\text { Tested } \\
\text { profile }\end{array}$ & Species profile & $p$-Value & $D$ \\
\hline \multirow{13}{*}{$\begin{array}{l}\text { EWM } \\
\text { SMALL1 vs }\end{array}$} & EWM_SMALL1 & NA & NA & \multirow{13}{*}{$\begin{array}{l}\text { EWM } \\
\text { ELODEA vs }\end{array}$} & EWM_SMALL1 & 0.1678 & 0.5 \\
\hline & EWM_ELODEA & 0.1678 & 0.5 & & EWM_ELODEA & NA & NA \\
\hline & EWM_SMALL2 & 0.1678 & 0.5 & & EWM_SMALL2 & 0.7869 & 0.3 \\
\hline & ELODEA_MIXED & 0.4175 & 0.4 & & ELODEA_MIXED & 0.4175 & 0.4 \\
\hline & LOWVEG1 & 0.4175 & 0.4 & & LOWVEG1 & 0.4175 & 0.4 \\
\hline & CURLY_EWM & 0.4175 & 0.4 & & CURLY_EWM & 0.9945 & 0.2 \\
\hline & EWM & 0.4175 & 0.4 & & EWM & 0.4175 & 0.4 \\
\hline & CHARA1 & 0.01234 & $0.7^{*}$ & & CHARA1 & 0.0002165 & 0.9 ** \\
\hline & CHARA2 & 0.1678 & 0.5 & & CHARA2 & 0.01234 & $0.7^{*}$ \\
\hline & EWM_CHARA & 0.01234 & $0.7^{*}$ & & EWM_CHARA & 0.0002165 & $0.9^{\star \star}$ \\
\hline & LOWVEG2 & 0.002017 & $0.8^{* * *}$ & & LOWVEG2 & 0.0002165 & $0.9^{* *}$ \\
\hline & LOWVEG3 & 0.01234 & $0.7^{*}$ & & LOWVEG3 & 0.0002165 & $0.9^{* *}$ \\
\hline & LOWVEG4 & 0.01234 & 0.7 * & & LOWVEG4 & 0.0002165 & 0.9 ** \\
\hline \multirow{13}{*}{$\begin{array}{l}\text { EWM } \\
\text { SMALL2 vs }\end{array}$} & EWM_SMALL1 & 0.1678 & 0.5 & \multirow{13}{*}{$\begin{array}{l}\text { CURLY } \\
\text { EWM vs }\end{array}$} & EWM_SMALL1 & 0.4175 & 0.4 \\
\hline & EWM_ELODEA & 0.7869 & 0.3 & & EWM_ELODEA & 0.9945 & 0.2 \\
\hline & EWM_SMALL2 & & NA & & EWM_SMALL2 & 0.4175 & 0.4 \\
\hline & ELODEA_MIXED & 0.05245 & 0.6 & & ELODEA_MIXED & 0.7869 & 0.3 \\
\hline & LOWVEG1 & 0.05245 & 0.6 & & LOWVEG1 & 0.7869 & 0.3 \\
\hline & CURLY_EWM & 0.4175 & 0.4 & & CURLY_EWM & & NA \\
\hline & EWM & 0.05245 & 0.6 & & EWM & 0.7869 & 0.3 \\
\hline & CHARA1 & 0.0002165 & ** & & CHARA1 & 0.002057 & $0.8^{* * *}$ \\
\hline & CHARA2 & 0.002057 & $0.8^{* * *}$ & & CHARA2 & 0.002057 & $0.8^{* \star *}$ \\
\hline & EWM_CHARA & 0.0002165 & 0.9 ** & & EWM_CHARA & 0.002057 & $0.8^{* * *}$ \\
\hline & LOWVEG2 & 0.0002165 & $0.9^{* *}$ & & LOWVEG2 & 0.002057 & $0.8^{* \star *}$ \\
\hline & LOWVEG3 & 0.0002165 & $0.9^{* *}$ & & LOWVEG3 & 0.002057 & $0.8^{* * *}$ \\
\hline & LOWVEG4 & 0.0002165 & $0.9^{* *}$ & & LOWVEG4 & 0.002057 & $0.8^{\star \star \star}$ \\
\hline
\end{tabular}


Brooks et al.: Multiscale collection and analysis of submerged aquatic vegetation...

Table 4 (Continued).

\begin{tabular}{|c|c|c|c|c|c|c|c|}
\hline $\begin{array}{l}\text { Tested } \\
\text { profile }\end{array}$ & Species profile & $p$-Value & $D$ & $\begin{array}{l}\text { Tested } \\
\text { profile }\end{array}$ & Species profile & $p$-Value & $D$ \\
\hline \multirow[t]{13}{*}{ EWM vs } & EWM_SMALL1 & 0.4175 & 0.4 & \multirow{13}{*}{$\begin{array}{l}\text { EWM } \\
\text { CHARA vs }\end{array}$} & EWM_SMALL1 & 0.01234 & $0.7^{*}$ \\
\hline & EWM_ELODEA & 0.4175 & 0.4 & & EWM_ELODEA & 0.0002165 & 0.9 ** \\
\hline & EWM_SMALL2 & 0.05245 & 0.6 & & EWM_SMALL2 & 0.0002165 & 0.9 ** \\
\hline & ELODEA_MIXED & 0.9945 & 0.2 & & ELODEA_MIXED & 0.05245 & 0.6 \\
\hline & LOWVEG1 & 0.9945 & 0.2 & & LOWVEG1 & 0.05245 & 0.6 \\
\hline & CURLY_EWM & 0.7869 & 0.3 & & CURLY_EWM & 0.002057 & $0.8^{* \star *}$ \\
\hline & EWM & & NA & & EWM & 0.05245 & 0.6 \\
\hline & CHARA1 & 0.05245 & 0.6 & & CHARA1 & 0.9945 & 0.2 \\
\hline & CHARA2 & 0.002057 & $0.8^{\star * *}$ & & CHARA2 & 0.7869 & 0.3 \\
\hline & EWM_CHARA & 0.05245 & 0.6 & & EWM_CHARA & NA & NA \\
\hline & LOWVEG2 & 0.05245 & 0.6 & & LOWVEG2 & 0.9945 & 0.2 \\
\hline & LOWVEG3 & 0.05245 & 0.6 & & LOWVEG3 & 0.9945 & 0.2 \\
\hline & LOWVEG4 & 0.05245 & 0.6 & & LOWVEG4 & 0.9945 & 0.2 \\
\hline
\end{tabular}

Note: NA, not applicable (same profile).

*Significant at $p<0.05$.

** Significant at $p<0.01$

${ }^{\star \star \star}$ Significant at $p<0.001$.

We hypothesized that the July 2017 spectral data might show a more distinct pattern for EWM, because the vegetation would be more fully developed (taller, denser) a month later than the relatively early in the growing season June 2017 data. Also, the June samples were collected during overcast days, whereas most of the July samples were collected on sunny days. However, as shown in Table 5, areas with significant amounts of EWM only looked different than one of the OPEN areas, and then only for three of the four EWM-dominated areas.

\subsection{Comparison of Spectral Profile Results across Scale-Based Collection Methods}

In the June 2017 data collection, all three methods of spectral data collection were deployed. This enabled comparison of the EWM spectral data (shown in Table 6) at three different scales, using the single-factor ANOVA, TukeyHSD, and Tukey-Kramer methods, as described in Sec. 3.3. Figure 8 shows the spectral profiles for the six tetracam bands, and the ratios/indices used across analyses.

In Fig. 8(a), there is a clear difference between the relatively low reflectance values for EWM seen in the OOW spectra and the higher values for the boatside and UAS spectra. Table 6 shows the UAS reflectance for the six Tetracam bands average $13.3 \%$ of the boatside reflectance and $27.4 \%$ of the OOW values. For the ratio and indices, UAS values average $38.6 \%$ of the boatside values and $12.0 \%$ of the OOW values. The boatside reflectance values are generally greater than the OOW values (an average of $202.2 \%$ for the six Tetracam bands) but are lower (32.7\% average) for the ratio and indices.

Table 7 shows the results of comparing EWM spectral reflectance values for the three spectral data collection methods. For all of the Tetracam wavelengths and the RE/BLUE ratio, the means of the groups were not equal (see ANOVA results for $p$-values in bold). Since the null hypothesis of equal group means could not be rejected for the mNDVI, mNDAVI, and mWAVI indices, it was not appropriate to apply the post-hoc TukeyHSD or Tukey-Kruskal procedures to these 
Brooks et al.: Multiscale collection and analysis of submerged aquatic vegetation...

Table 5 K-S test of July 2017 UAS-based spectral data resampled to Tetracam bands plus ratios.

\begin{tabular}{|c|c|c|c|c|c|c|c|}
\hline $\begin{array}{l}\text { Tested } \\
\text { profile }\end{array}$ & Species profile & $p$-Value & $D$ & $\begin{array}{l}\text { Tested } \\
\text { profile }\end{array}$ & Species profile & $p$-Value & $D$ \\
\hline \multirow{8}{*}{$\begin{array}{l}\text { OPEN_- } \\
\text { EWM1 vs }\end{array}$} & OPEN_EWM1 & NA & NA & \multirow[t]{8}{*}{ EWM vs } & OPEN_EWM1 & 0.4175 & 0.4 \\
\hline & EWM & 0.4175 & 0.4 & & EWM & NA & NA \\
\hline & CHARA & 0.4175 & 0.4 & & CHARA & 0.4175 & 0.4 \\
\hline & ELODEA_EWM & 0.9945 & 0.2 & & ELODEA_EWM & 0.4175 & 0.4 \\
\hline & $\begin{array}{l}\text { ELODEA } \\
\text { FLATSTEM }\end{array}$ & 0.9945 & 0.2 & & $\begin{array}{l}\text { ELODEA } \\
\text { FLATSTEM }\end{array}$ & 0.4175 & 0.4 \\
\hline & OPEN1 & 0.05245 & 0.6 & & OPEN1 & 0.1678 & 0.5 \\
\hline & OPEN_EWM2 & 0.4175 & 0.4 & & OPEN_EWM2 & 0.4175 & 0.4 \\
\hline & OPEN2 & 0.4175 & 0.4 & & OPEN2 & 0.002017 & $0.8^{* *}$ \\
\hline \multirow{8}{*}{$\begin{array}{l}\text { ELODEA } \\
\text { EWM vs }\end{array}$} & OPEN_EWM1 & 0.9945 & 0.2 & \multirow{8}{*}{$\begin{array}{l}\text { OPEN_- } \\
\text { EWM2 vs }\end{array}$} & OPEN_EWM1 & 0.4175 & 0.4 \\
\hline & EWM & 0.4175 & 0.4 & & EWM & 0.4175 & 0.4 \\
\hline & CHARA & 0.4175 & 0.4 & & CHARA & 0.1678 & 0.5 \\
\hline & ELODEA_EWM & NA & NA & & ELODEA_EWM & 0.1678 & 0.5 \\
\hline & $\begin{array}{l}\text { ELODEA } \\
\text { FLATSTEM }\end{array}$ & 0.4175 & 0.3 & & $\begin{array}{l}\text { ELODEA- } \\
\text { FLATSTEM }\end{array}$ & 0.1678 & 0.5 \\
\hline & OPEN1 & 0.05245 & 0.6 & & OPEN1 & 0.05245 & 0.6 \\
\hline & OPEN_EWM2 & 0.1678 & 0.5 & & OPEN_EWM2 & NA & NA \\
\hline & OPEN2 & 0.002057 & $0.8^{* *}$ & & OPEN2 & 0.002057 & $0.8^{* *}$ \\
\hline
\end{tabular}

Note: NA, not applicable (same profile).

*Significant at $p<0.05$.

**Significant at $p<0.01$.

$\star \star \star$ Significant at $p<0.001$.

data. Using the TukeyHSD procedure, the UAS versus boatside group means were consistently different for the 490- to 720-nm Tetracam wavelengths but not for the RE/BLUE ratio. OOW versus UAS group means were sometimes different for the 530-, 550-, 600-, and 720-nm wavelengths, and the RE/BLUE ratio but not for 490- or 680-nm wavelengths. OOW versus boatside group means were only different for the RE/BLUE ratio in the TukeyHSD results. The UAS versus boatside results were similar for the Tukey-Kruskal results with 490- to 680-nm group means being different but not for $720 \mathrm{~nm}$. None of the OOW versus boatside and OOW versus UAS group means were different using Tukey-Kruskal.

\subsection{Discussion of Spectral Profile Results and Analysis}

For all tested datasets, using all available 1-nm bands resulted in spectral profiles being different (for example, for the OOW data in Fig. 4 and boatside data in Fig. 6). However, deploying an imaging system for mapping in the field that would use over 600 bands is not yet practical. By contrast, using only the Tetracam or Becker bands rarely resulted in EWM being distinguished reliably from other vegetation (Fig. 5). One of the UAS datasets, from June 2017, did show that using the Tetracam bands plus the RE/BLUE, mNDVI, mNDAVI, and mWAVI indices could differentiate EWM in 6 of 12 vegetation type comparisons (Table 4).

This could not be repeated in a similar dataset from a month later (Table 5). An analysis of 65 bands (the 651 bands from a June 2017 OOW dataset averaged to 10-nm wide) did show reliable separability of EWM from eight other vegetation spectral profiles including seven different species (Table 2). With hyperspectral imaging systems capable of 40 to 80 bands reaching 
Brooks et al.: Multiscale collection and analysis of submerged aquatic vegetation...

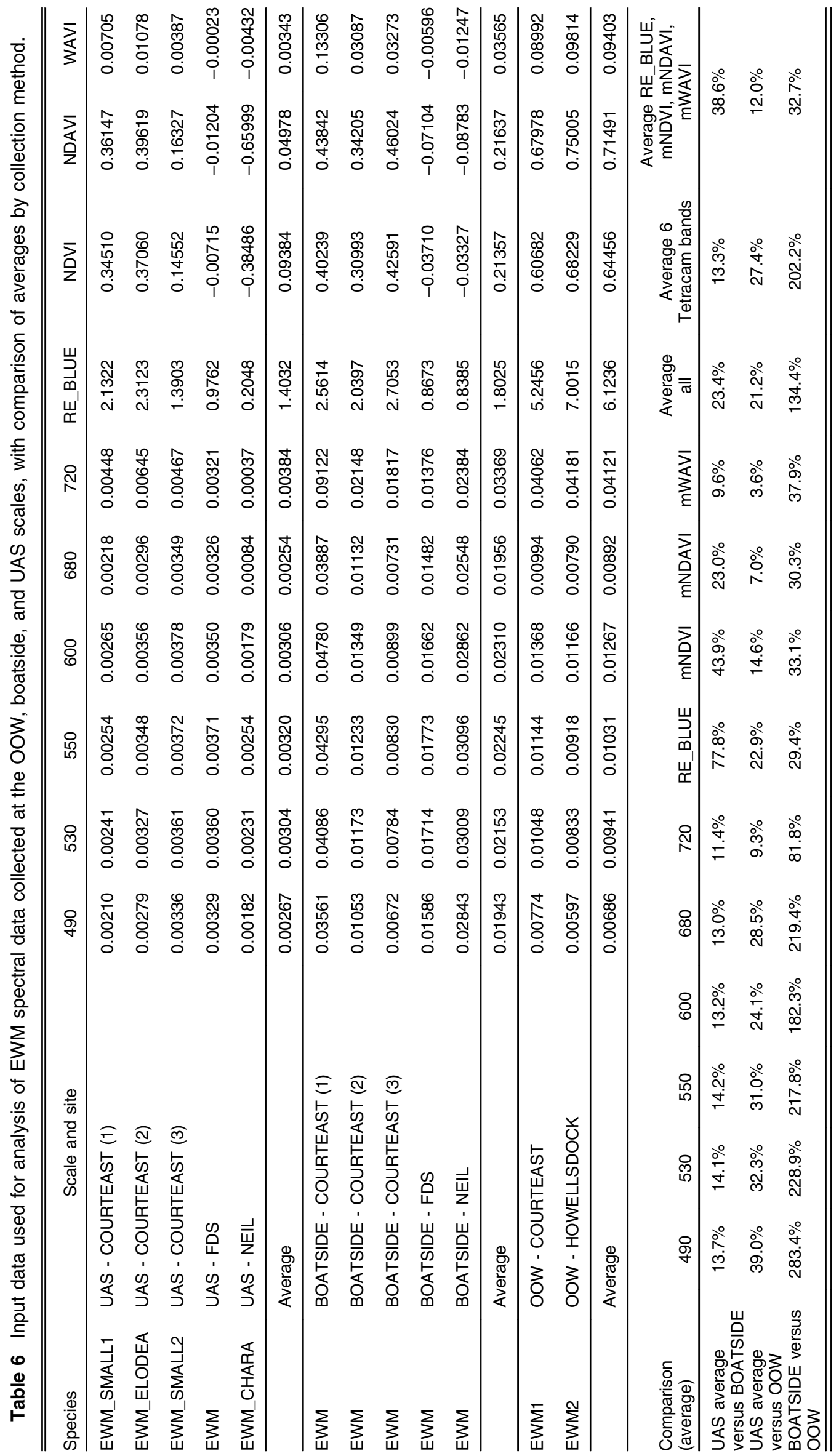


Brooks et al.: Multiscale collection and analysis of submerged aquatic vegetation...
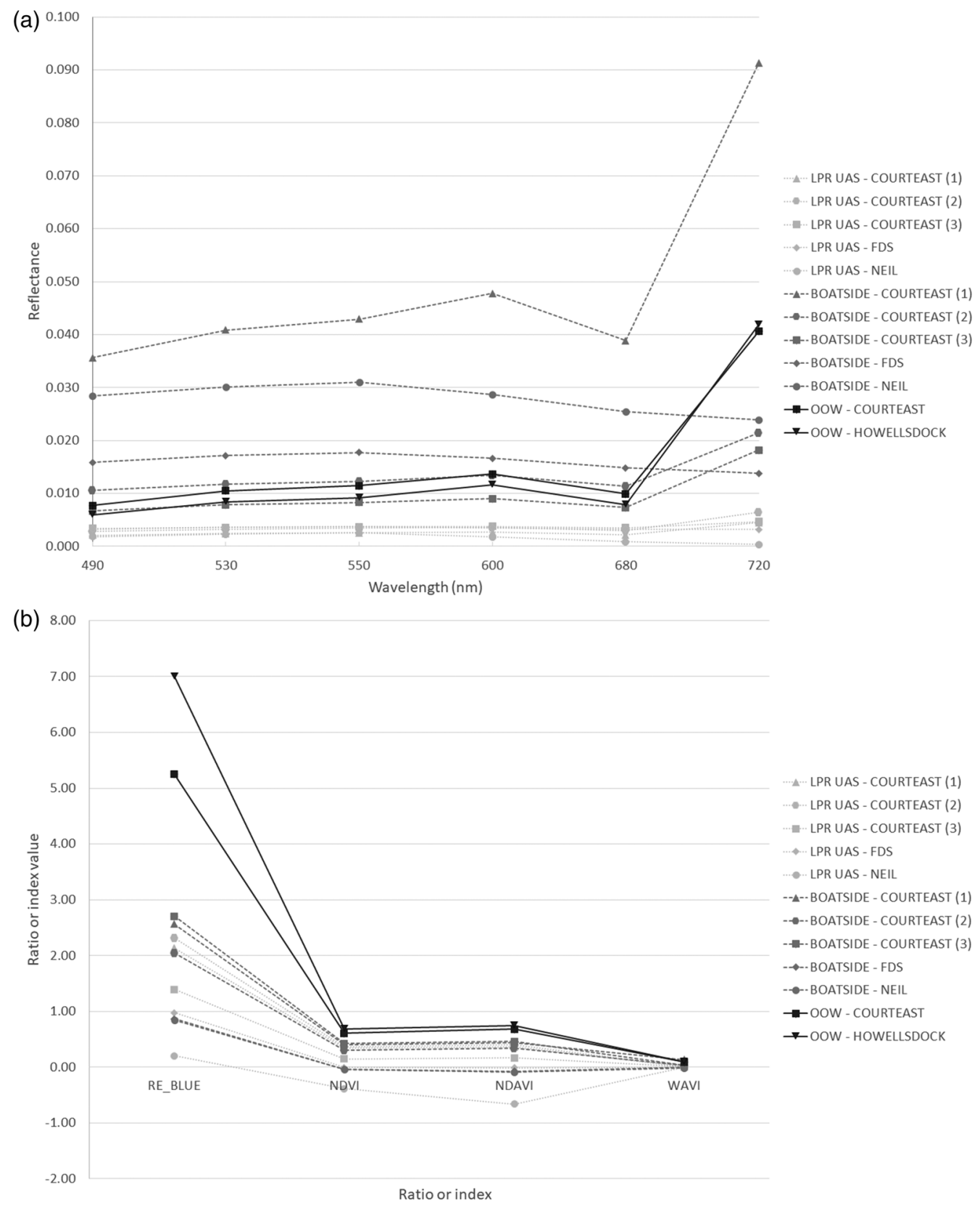

Fig. 8 Comparison of spectral profiles for June 2017 across three methods of sampling: (a) for the six tetracam bands and (b) for the ratio and indices.

costs of US $\$ 25,000$ to $\$ 40,000$, this level of band imaging may be more practical for deployment in EWM mapping and monitoring efforts.

For distinguishing EWM from other vegetation, the ANOVA mixed model analysis showed that the mNDVI ratio is important (Table 3 ) but that individual Tetracam bands or the RE/BLUE ratio and aquatic-specific mNDAVI and mWAVI indices were not helpful. As noted, NDVI was originally developed as a method of identifying areas of relatively lower or higher green biomass for terrestrial systems in satellite imagery using NIR and red bands. It appears that the spectral profiling is picking up different amounts of biomass even for submerged aquatic vegetation, where light penetration in the red-edge to NIR range is limited relative to visible light bands. With mNDVI proving important to EWM detection, we compared the values of the available $720-\mathrm{nm}$ red-edge band to the infrared band of $780 \mathrm{~nm}$ for all the boatside data collections. The relationships between 720 and $780 \mathrm{~nm}$ are nearly linear, with all showing a strong $R^{2}$ 
Brooks et al.: Multiscale collection and analysis of submerged aquatic vegetation...

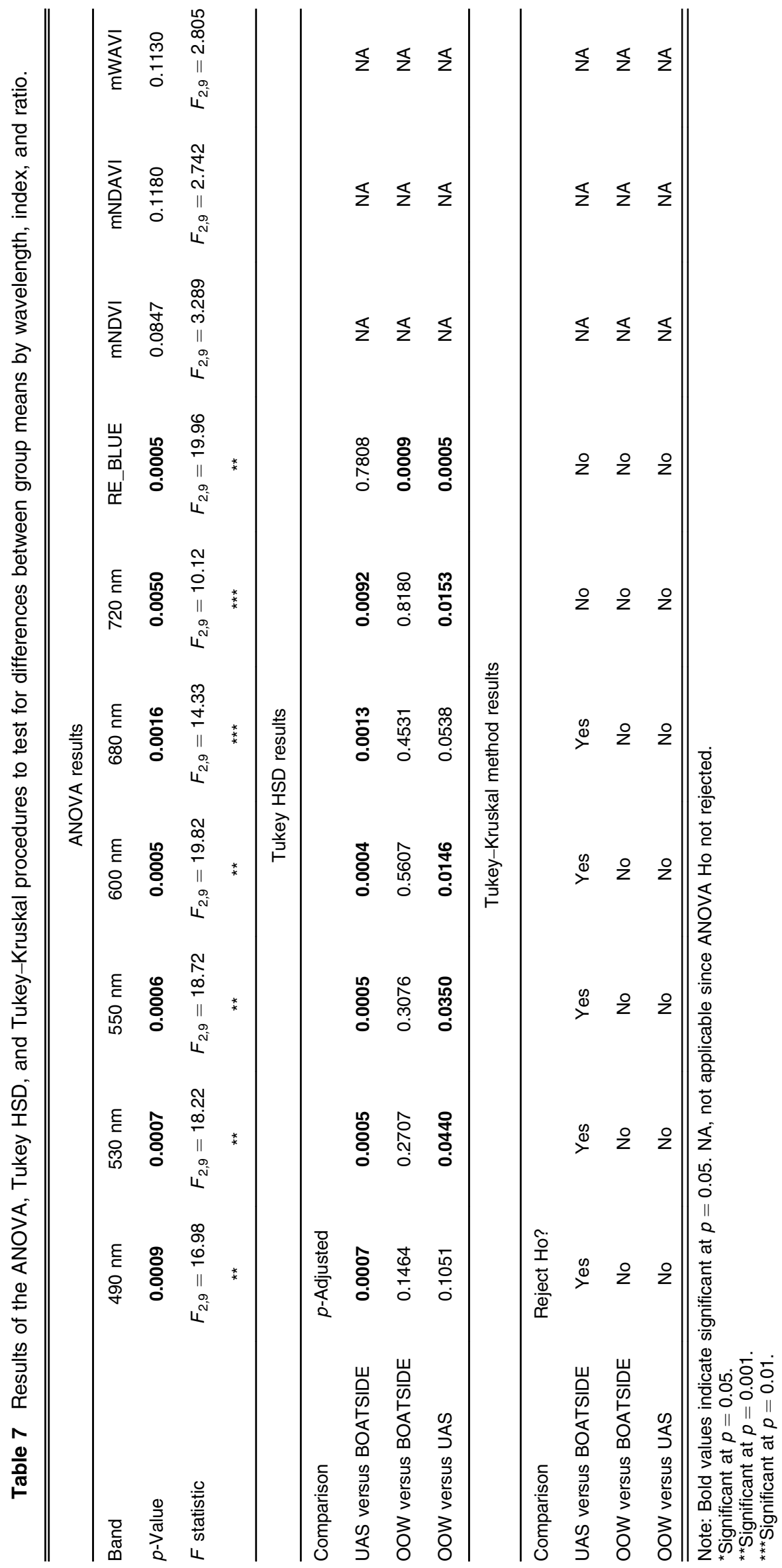


value, especially for August $2016\left(R^{2}=0.8681\right)$, June $2017\left(R^{2}=0.9979\right)$, July 2017 $\left(R^{2}=0.9548\right)$, and August $2017\left(R^{2}=0.9832\right)$. Only July 2016 falls below 0.85 , which a value of $R^{2}=0.7450$. Based on these results, $720 \mathrm{~nm}$ appears to be a reasonable substitute for $780 \mathrm{~nm}$ for NDVI-type calculations.

A comparison of EWM spectral profiles across the OOW, boatside, and UAS scales of data collection showed significantly lower $R_{\mathrm{rS}}$ values for the UAS method versus the OOW and boatside methods (Table 6). The lower values for the UAS are probably caused by the greater distance to the spectroradiometer sensor (10 to $15 \mathrm{~m}$ from the UAS) compared to the OOW and boatside data, where the sensor is very close (one $\mathrm{m}$ or less) to the vegetation being sampled. This could mean that it is harder to identify species when 10 to $15 \mathrm{~m}$ in the air versus sensing from boatside scales. Maximizing the amount of information reaching an UAS-based imaging sensor by collecting on sunny days, near solar noon, and with relatively calm waters should help minimize the impact of this more distant method of vegetation profiling. These methods can help take advantage of the ability of UAS to cover larger areas than boat-based sampling in a relatively short amount of time.

The comparison of EWM spectra across the three data collection methods indicated that the spectral results are different for the Tetracam bands and the RE/BLUE ratio but not for the mNDVI, mNDAVI, and mWAVI indices (Table 7). For the Tetracam wavelengths, the average values are different for most wavelengths versus the OOW and boatside scale. The OOW and boatside data appear to be similar for EWM samples across scales. With the mNDVI, mNDAVI, and mWAVI indices not being significantly different, this suggests that these values may be scale independent and more appropriate for EWM identification than relying on spectral bands alone. Tying these results together with the boatside ANOVA mixed model results, mNDVI again appears important for reliable EWM identification.

\subsection{Research Directions}

Related research is underway to use the methods and results described here to develop an EWM mapping algorithm and apply it for mapping EWM extent for nearshore locations in the Laurentian Great Lakes region. The EWM algorithm combined with the UAS-based platform is intended to provide a monitoring tool for evaluating the effectiveness of EWM treatment methods (such as herbicide spraying, mechanical harvesting, and biocontrol) and for investigating areas at risk of invasion or reoccurrence.

To move this research direction forward, a preliminary proof-of-concept example of mapping EWM from a UAS-collected image was completed, pending development of the spectrally-based EWM-specific algorithm. As noted above, with the UAS flights, $5 \mathrm{mp}$ images were taken over the area, where the OceanOptics spectral data were being recorded to help record the footprint of the LPR sensor. Figure 9 shows one of those images analyzed using Trimble eCognition objectbased image classification software (Trimble Inc., Sunnyvale, California), where EWM formed the dominant visible SAV. Images were location tagged using global position system data with height recorded, and based on the known sensor size, we could, therefore, appropriately scale the images in ESRI Desktop ArcGIS software, version 10.5.1. Using the visible RGB imagery data from the LPR system's digital photos, it was possible to differentiate the image into water, shallower submerged EWM (dark green), deeper areas of SAV that were most likely EWM (grey) and water (blue), with some small surface floating non-EWM vegetation also identified. These results show promise for extending them to a larger mapping effort covering the Les Cheneaux Islands and similar areas, at least for where EWM is spectrally different than surrounding cover types.

Another research direction is accounting for the impact of water characteristics on the identification of EWM versus other SAV species. As part of the larger project study, data on light conditions and water characteristics have been collected on the same days as the spectral profile data, generally within $2 \mathrm{~h}$ of the spectral collections. For mapping SAV, it is likely to be important to consider the impacts of the attenuating and backscattering features of water that reduce the strength of the plant species' spectral signature versus standard terrestrial spectrometry. Nearshore "case 2" waters can be complex, with chlorophyll, color dissolved organic matter, and suspended minerals dominating the water color constituents. ${ }^{68,69}$ These can cause significant 


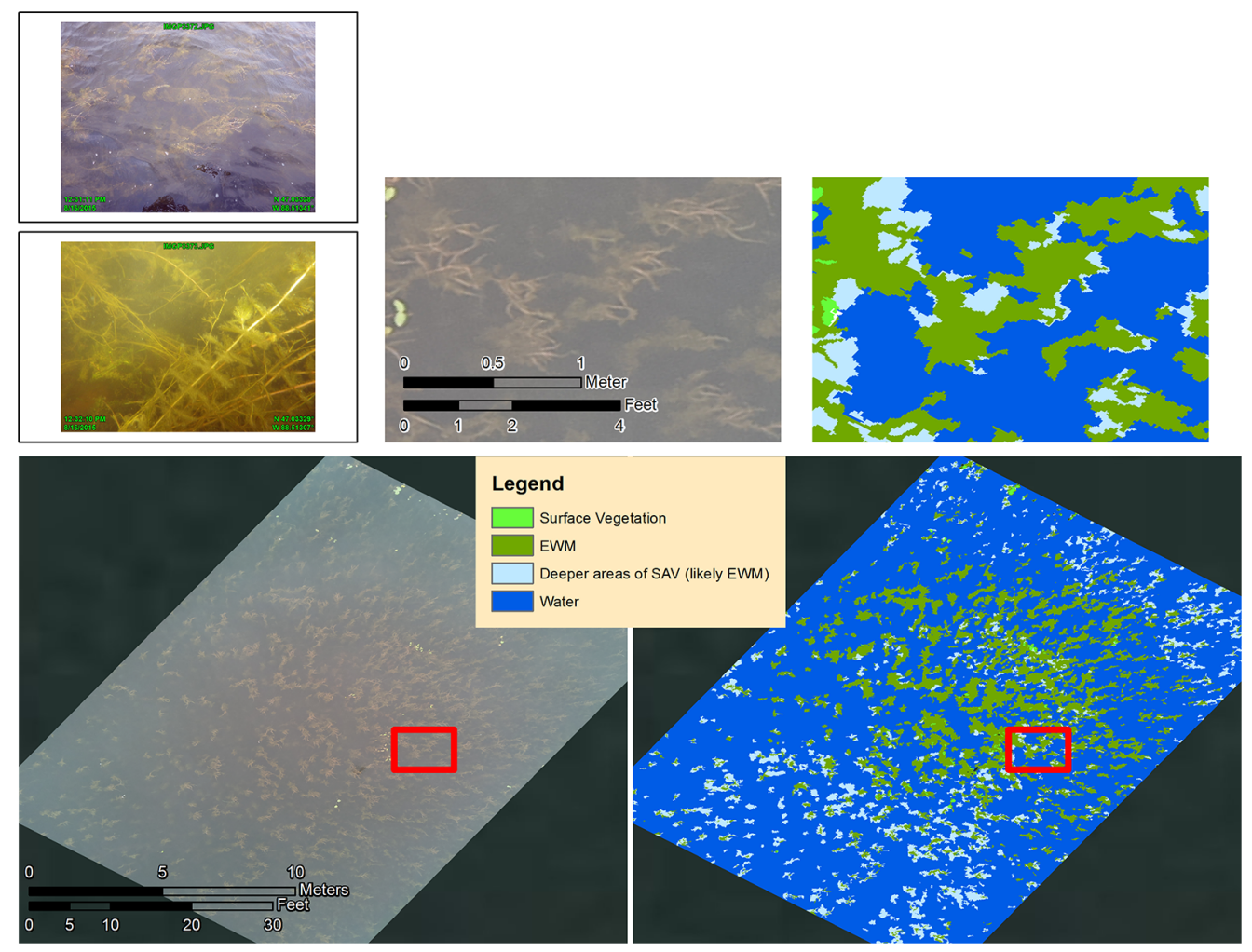

Fig. 9 UAS-collected RGB image of predominantly EWM using an eCognition object-based classification into four class types. Area in red (at bottom) is enlarged in the top two images. Field images at the top left demonstrate that the EWM being mapped is submergent.

attenuation of the remote sensing signal from underwater features. Understanding how water chemistry and light characteristics are affecting the vegetation signal reaching the remote sensors is an important consideration for SAV mapping research and will be addressed in the related research.

\section{Conclusion}

Detailed, multiscale spectral data provided the ability to understand whether and how EWM can be spectrally distinguished from other species. Spectral differences exist between EWM and other SAV species in certain datasets, but the number of bands and types of indices used is important. It appears likely that sky conditions are having impacts on at least some spectral profiles, but data were preserved for analysis to understand if EWM could be detected under a variety of conditions. Hyperspectral-level data, such as the 65 resampled 10-nm bands used here, showed that EWM can be separated from other species when using detailed spectral information. An analysis of six multispectral bands corresponding to those of a UAS-mountable multispectral camera plus ratio and vegetation indices showed that mNDVI was critical in being able to differentiate EWM from other SAV and bottom types. It is likely that mNDVI is sensitive to the denser biomass of EWM that can grow near the water's surface, forming a canopy overtopping other vegetation types near the water's surface (i.e., within $\sim 1 \mathrm{~m}$ ). Because red-edge and red light have limited but sufficient penetration in these shallow depths, mNDVI is able to discriminate EWM from non-EWM. mNDVI was part of the group of ratios, whose reflectance values did not differ significantly for EWM across the three data collection methods, indicating that it should be a useful scale-independent metric for identifying EWM. mNDVI and other metrics that include red and infrared wavelengths are likely to be key elements of a mapping algorithm used for monitoring the extent of EWM and changes in response to treatment efforts.

Analyzing EWM spectral data at the OOW, boatside, and UAS scales showed a reduced strength of signal for the UAS results versus other methods, with OOW and boatside methods producing similar results. Using boatside sampling appears to provide the same value as 
removing the vegetation from the water and then creating spectral profiles. The mNDVI, mNDAVI, and mWAVI EWM spectral data were similar across data collection methods, meaning these may provide a scale-independent method of EWM spectral profiling and mapping that can be applied to UAS-based mapping and monitoring of invasive SAV.

Data collected at the UAS scale can cover larger areas than boatside methods or taking vegetation out of the water to identify it for mapping. With sufficient spectral bands and use of mNDVI, UAS-based imagery data are likely to provide the needed mapping information for monitoring EWM over areas larger than individual treatment locations. For imaging of EWM sites, this can mean either flying relatively low $(10 \mathrm{~m})$ to provide single-species, high-resolution mapping capability. However, the weaker signal of the UAS-collected data means that if identifying the spectral profile of underwater vegetation is the most critical element, then the boatside scale is likely to be the most useful since it provides higher-resolution information with a reduced chance for multiple species forming a part of the spectral profile and image, particularly if only small areas need to be monitored.

\section{Acknowledgments}

This project has been funded by the United States Environmental Protection Agency under assistance agreement 00E01928 to Michigan Technological University. The contents of this document do not necessarily reflect the views and policies of the Environmental Protection Agency nor does the EPA endorse trade names or recommend the use of commercial products mentioned in this document. Support was provided by the Michigan Tech Research Institute and the Biological Sciences Department of Michigan Technological University.

\section{References}

1. E. Jeppesen et al., The Structuring Role of Submerged Macrophytes in Lakes, Springer Science \& Business Media, New York (2012).

2. L. P. Rozas and W. E. Odum, "Occupation of submerged aquatic vegetation by fishes: testing the roles of food and refuge," Oecologia 77(1), 101-106 (1988).

3. Y. Vadeboncoeur, P. B. McIntyre, and M. J. V. Zanden, "Borders of biodiversity: life at the edge of the world's large lakes," BioScience 61(7), 526-537 (2011).

4. S. R. Carpenter and D. M. Lodge, "Effects of submersed macrophytes on ecosystem processes," Aquat. Bot. 26, 341-370 (1986).

5. A. M. Marcarelli and W. A. Wurtsbaugh, "Nitrogen fixation varies spatially and seasonally in linked stream-lake ecosystems," Biogeochemistry 94(2), 95-110 (2009).

6. J. P. Ziegler et al., "Macrophyte biomass predicts food chain length in shallow lakes," Ecosphere 6(1), 1-16 (2015).

7. A. S. Trebitz and D. L. Taylor, "Exotic and invasive aquatic plants in Great Lakes coastal wetlands: distribution and relation to watershed land use and plant richness and cover," J. Great Lakes Res. 33(4), 705-721 (2007).

8. M. S. Ailstock, C. M. Norman, and P. J. Bushmann, "Common reed Phragmites Australis: control and effects upon biodiversity in freshwater nontidal wetlands," Restor. Ecol. 9(1), 49-59 (2001).

9. K. M. Kettenring and C. R. Adams, "Lessons learned from invasive plant control experiments: a systematic review and meta-analysis," J. Appl. Ecol. 48(4), 970-979 (2011).

10. L. S. Nelson and J. Shearer, "2, 4-D and Mycoleptodiscus terrestris for control of Eurasian watermilfoil," J. Aquat. Plant Manage. 43, 29-34 (2005).

11. C. Tucker, "Efficiency of diver-assisted suction harvesting (DASH) of invasive milfoil in New Hampshire waterbodies," Thesis, p. 25, Carthage College (2017).

12. K. I. Wagner et al., "Whole-lake herbicide treatments for Eurasian watermilfoil in four Wisconsin lakes: effects on vegetation and water clarity," Lake Reservoir Manage. 23(1), 83-94 (2007).

13. L. S. W. Group, "Lake superior aquatic invasive species complete prevention plan," Lake Superior Binational Program (2014). 
Brooks et al.: Multiscale collection and analysis of submerged aquatic vegetation...

14. L. A. Buchan and D. K. Padilla, "Predicting the likelihood of Eurasian watermilfoil presence in lakes, a macrophyte monitoring tool," Ecol. Appl. 10(5), 1442-1455 (2000).

15. E. Adam, O. Mutanga, and D. Rugege, "Multispectral and hyperspectral remote sensing for identification and mapping of wetland vegetation: a review," Wetlands Ecol. Manage. 18(3), 281-296 (2010).

16. S. L. Ozesmi and M. E. Bauer, "Satellite remote sensing of wetlands," Wetlands Ecol. Manage. 10(5), 381-402 (2002).

17. T. S. Silva et al., "Remote sensing of aquatic vegetation: theory and applications," Environ. Monit. Assess. 140(1-3), 131-145 (2008).

18. L. Bourgeau-Chavez et al., "Development of a bi-national Great Lakes coastal wetland and land use map using three-season PALSAR and Landsat imagery," Remote Sens. 7(7), 8655-8682 (2015).

19. S. Ackleson and V. Klemas, "Remote sensing of submerged aquatic vegetation in lower Chesapeake Bay: a comparison of Landsat MSS to TM imagery," Remote Sens. Environ. 22(2), 235-248 (1987).

20. C. Brooks et al., "A satellite-based multi-temporal assessment of the extent of nuisance Cladophora and related submerged aquatic vegetation for the Laurentian Great Lakes," Remote Sens. Environ. 157, 58-71 (2015).

21. R. A. Shuchman, M. J. Sayers, and C. N. Brooks, "Mapping and monitoring the extent of submerged aquatic vegetation in the Laurentian Great Lakes with multi-scale satellite remote sensing," J. Great Lakes Res. 39, 78-89 (2013).

22. S. Ashraf et al., "Satellite remote sensing for mapping vegetation in New Zealand freshwater environments: a review," New Zealand Geogr. 66(1), 33-43 (2010).

23. J. D. Midwood and P. Chow-Fraser, "Mapping floating and emergent aquatic vegetation in coastal wetlands of Eastern Georgian Bay, Lake Huron, Canada," Wetlands 30(6), 11411152 (2010).

24. O. K. Dogan, Z. Akyurek, and M. Beklioglu, "Identification and mapping of submerged plants in a shallow lake using quickbird satellite data," J. Environ. Manage. 90(7), 2138-2143 (2009).

25. P. T. Wolter, C. A. Johnston, and G. J. Niemi, "Mapping submergent aquatic vegetation in the US Great Lakes using Quickbird satellite data," Int. J. Remote Sens. 26(23), 5255-5274 (2005).

26. C. Fritz et al., "Mapping submerged aquatic vegetation using RapidEye satellite data: the example of Lake Kummerow (Germany)," Water 9(7), 510 (2017).

27. H. Dierssen, A. Chlus, and B. Russell, "Hyperspectral discrimination of floating mats of seagrass wrack and the macroalgae Sargassum in coastal waters of Greater Florida Bay using airborne remote sensing," Remote Sens. Environ. 167, 247-258 (2015).

28. K. F. Flynn and S. C. Chapra, "Remote sensing of submerged aquatic vegetation in a shallow non-turbid river using an unmanned aerial vehicle," Remote Sens. 6(12), 12815-12836 (2014).

29. A. Hodgson, N. Kelly, and D. Peel, "Unmanned aerial vehicles (UAVs) for surveying marine fauna: a dugong case study," PLoS One 8(11), e79556 (2013).

30. C. Zeng, M. Richardson, and D. J. King, "The impacts of environmental variables on water reflectance measured using a lightweight unmanned aerial vehicle (UAV)-based spectrometer system," ISPRS J. Photogramm. Remote Sens. 130, 217-230 (2017).

31. K. Anderson and K. J. Gaston, "Lightweight unmanned aerial vehicles will revolutionize spatial ecology," Front. Ecol. Environ. 11(3), 138-146 (2013).

32. J. V. Marcaccio, C. E. Markle, and P. Chow-Fraser, "Unmanned aerial vehicles produce high-resolution, seasonally-relevant imagery for classifying wetland vegetation," ISPRS-Int. Arch. Photogramm. Remote Sens. Spatial Inf. Sci. XL-1/W4, 249-256 (2015).

33. J. Penuelas et al., "Assessing community type, plant biomass, pigment composition, and photosynthetic efficiency of aquatic vegetation from spectral reflectance," Remote Sens. Environ. 46(2), 110-118 (1993).

34. F. D. Van der Meer et al., "Multi-and hyperspectral geologic remote sensing: a review," Int. J. Appl. Earth Obs. Geoinf. 14(1), 112-128 (2012).

35. D. J. Williams et al., "Preliminary investigation of submerged aquatic vegetation mapping using hyperspectral remote sensing," Environ. Monit. Assess. 81(1-3), 383-392 (2003). 
36. J. H. Everitt et al., "Evaluation of hyperspectral reflectance data for discriminating six aquatic weeds," J. Aquat. Plant Manage. 49, 94-100 (2011).

37. H. J. Cho, P. Kirui, and H. Natarajan, "Test of multi-spectral vegetation index for floating and canopy-forming submerged vegetation," Int. J. Environ. Res. Public Health 5(5), 477-483 (2008).

38. E. Underwood et al., "Mapping invasive aquatic vegetation in the Sacramento-San Joaquin Delta using hyperspectral imagery," Environ. Monit. Assess. 121(1-3), 47-64 (2006).

39. E. Adam and O. Mutanga, "Spectral discrimination of papyrus vegetation (Cyperus papyrus L.) in swamp wetlands using field spectrometry," ISPRS J. Photogramm. Remote Sens. 64(6), 612-620 (2009).

40. F. J. Artigas and J. Yang, "Spectral discrimination of marsh vegetation types in the New Jersey Meadowlands, USA," Wetlands 26(1), 271-277 (2006).

41. L. Yuan and L.-Q. Zhang, "Mapping large-scale distribution of submerged aquatic vegetation coverage using remote sensing," Ecol. Inf. 3(3), 245-251 (2008).

42. R. W. Sawtell et al., "Real time HABs mapping using NASA Glenn hyperspectral imager," J. Great Lakes Res. 45, 596-608 (2019).

43. C. Yang et al., "Analysis of seagrass reflectivity by using a water column correction algorithm," Int. J. Remote Sens. 31(17-18), 4595-4608 (2010).

44. R. H. Becker et al., "Unmanned aerial system based spectroradiometer for monitoring harmful algal blooms: a new paradigm in water quality monitoring," J. Great Lakes Res. 45, 444-453 (2019).

45. M. S. Kearney et al., "The effects of tidal inundation on the reflectance characteristics of coastal marsh vegetation," J. Coastal Res. 25, 1177-1186 (2009).

46. C. J. Legleiter, D. A. Roberts, and R. L. Lawrence, "Spectrally based remote sensing of river bathymetry," Earth Surf. Processes Landforms 34(8), 1039-1059 (2009).

47. T. Malthus and D. George, "Airborne remote sensing of macrophytes in Cefni Reservoir, Anglesey, UK," Aquat. Bot. 58(3-4), 317-332 (1997).

48. D. R. Mishra et al., "Characterizing the vertical diffuse attenuation coefficient for downwelling irradiance in coastal waters: implications for water penetration by high resolution satellite data," ISPRS J. Photogramm. Remote Sens. 60(1), 48-64 (2005).

49. T. Allouis et al., "Comparison of LiDAR waveform processing methods for very shallow water bathymetry using Raman, near-infrared and green signals," Earth Surf. Processes Landforms 35(6), 640-650 (2010).

50. R. Dobson et al., "Collecting decision support system data through remote sensing of unpaved roads," Transp. Res. Rec. 2433, 108-115 (2014).

51. M. Moody and D. Les, "Geographic distribution and genotypic composition of invasive hybrid watermilfoil (Myriophyllum spicatum $\times$ M. sibiricum) populations in North America," Biol. Invasions 9(5), 559-570 (2007).

52. T. Zallek, "Intraspecific genetic variation, population structure, and performance of the invasive aquatic macrophyte Eurasian watermilfoil (Myriophyllum spicatum) in waterbodies with and without histories of chemical herbicide treatment across Michigan," in Dissertations, Master's Thesis and Master's Reports, Biological Sciences, p. 83, Michigan Technological University, Houghton, Michigan (2018).

53. F. Visser, C. Wallis, and A. M. Sinnott, "Optical remote sensing of submerged aquatic vegetation: opportunities for shallow clearwater streams," Limnologica 43(5), 388-398 (2013).

54. E. Vahtmäe and T. Kutser, "Classifying the Baltic Sea shallow water habitats using imagebased and spectral library methods," Remote Sens. 5(5), 2451-2474 (2013).

55. J. A. Johnson and R. Newman, "A comparison of two methods for sampling biomass of aquatic plants," J. Aquat. Plant Manage. 49(1), 1-8 (2011).

56. H. Hassani and E. S. Silva, "A Kolmogorov-Smirnov based test for comparing the predictive accuracy of two sets of forecasts," Econometrics 3(3), 590-609 (2015).

57. C. Brooks and A. M. Merenlender, "Determining the pattern of oak woodland regeneration for a cleared watershed in northwest California: a necessary first step for restoration," Restor. Ecol. 9(1), 1-12 (2001).

58. B. L. Becker, D. P. Lusch, and J. Qi, "Identifying optimal spectral bands from in situ measurements of Great Lakes coastal wetlands using second-derivative analysis," Remote Sens. Environ. 97(2), 238-248 (2005). 
Brooks et al.: Multiscale collection and analysis of submerged aquatic vegetation...

59. B. L. Becker, D. P. Lusch, and J. Qi, "A classification-based assessment of the optimal spectral and spatial resolutions for Great Lakes coastal wetland imagery," Remote Sens. Environ. 108(1), 111-120 (2007).

60. J. W. Rouse, Jr. et al., "Monitoring vegetation systems in the Great Plains with ERTS," in Goddard Space Flight Center 3d ERTS-1 Symp. (1974).

61. C. J. Tucker et al., "An extended AVHRR 8-km NDVI dataset compatible with MODIS and SPOT vegetation NDVI data," Int. J. Remote Sens. 26(20), 4485-4498 (2005).

62. Z.-T. Ouyang et al., "Spectral discrimination of the invasive plant Spartina alterniflora at multiple phenological stages in a saltmarsh wetland," PLoS One 8(6), e67315 (2013).

63. P. Villa et al., "Comparative assessment of broadband vegetation indices over aquatic vegetation," IEEE J. Sel. Top. Appl. Earth Obs. Remote Sens. 7(7), 3117-3127 (2014).

64. G. W. Oehlert, A First Course in Design and Analysis of Experiments, Freeman, New York (2010).

65. M. C. Whitlock and D. Schluter, The Analysis of Biological Data, 2nd ed., Roberts and Company Publishers, Greenwood Village, Colorado (2015).

66. J. J. Higgins, Introduction to Modern Nonparametric Statistics, Cengage Learning, Pacific Grove, California (2004).

67. J. Gower, S. King, and P. Goncalves, "Global monitoring of plankton blooms using MERIS MCI," Int. J. Remote Sens. 29(21), 6209-6216 (2008).

68. A. Morel and L. Prieur, "Analysis of variations in ocean color," Limnol. Oceanogr. 22(4), 709-722 (1977).

69. R. A. Shuchman et al., "An algorithm to retrieve chlorophyll, dissolved organic carbon, and suspended minerals from Great Lakes satellite data," J. Great Lakes Res. 39, 14-33 (2013).

Colin Brooks is a PhD candidate in biology at Michigan Technological University and received a master of environmental management from Duke University in 1993 and a bachelor of science in preforestry from Lenoir-Rhyne College in 1992. He is a senior research scientist at Michigan Tech Research Institute, Ann Arbor, Michigan, where he leads research on developing highresolution remote sensing methods, geospatial data visualization, and decision support systems, with a focus on the Great Lakes.

Amanda Grimm obtained her master's degree in natural resources and environment from the University of Michigan in 2011 and her bachelor's degree in environmental biology from Michigan State University in 2006. She is currently a research scientist at Michigan Technological University, Michigan Tech Research Institute, where her current research focuses on remote sensing of land cover, water quality, and coastal hazards.

Amy Marcarelli is an associate professor of biological sciences with over 20 years of research experience in stream and lake ecosystem ecology, carbon and nitrogen cycling, ecological restoration, and land-water interactions. She received her $\mathrm{PhD}$ in ecology from Utah State University in 2006 and her bachelor of arts in biology from Colgate University in 2000. She held a postdoctoral position at Idaho State University prior to her faculty appointment at Michigan Technological University in 2009.

Richard Dobson received his master of science in environmental science from the University of Michigan-Dearborn in 2013 and a bachelor of science in Earth science from the University of Michigan-Dearborn in 2007. He is a research scientist at Michigan Tech Research Institute, Ann Arbor, Michigan, where he has extensive experience in applying remote sensing techniques including UAS-enabled 3-D photogrammetry to condition assessment transportation assets and environmental research. 